\title{
Out-of-plane seismic response and failure mechanism of ma- sonry structures using finite elements with enhanced strain accuracy
}

\author{
Georgios Vlachakis ${ }^{1}$, Miguel Cervera ${ }^{1,2}$, Gabriel B. Barbat ${ }^{1}$, Savvas Saloustros $^{1 *}$
}

\author{
${ }^{1}$ Department of Civil and Environmental Engineering, Universitat Politècnica de Catalunya, UPC-Barce- \\ lonaTech, Campus Nord UPC, Jordi Girona 1-3, 08034 Barcelona, Spain. \\ ${ }^{2}$ CIMNE - International Center for Numerical Methods in Engineering, Campus Nord UPC, Gran \\ Capistà S/N, 08034 Barcelona, Spain
}

\begin{abstract}
The out-of-plane response is a complex and at the same time key aspect of the seismic vulnerability of masonry structures. It depends on several factors, some of which are the material properties, the quality of the walls, the geometry of the structure, the connections between structural elements and the stiffness of the diaphragms.

During the last years, a wide variety of numerical methods has been employed to assess the out-ofplane behaviour of unreinforced masonry structures. Finite element macro-modelling approaches are among the most famous as they allow modelling large structures at a reasonable computational cost. However, macro-modelling approaches may result in a non-realistic representation of localized cracks and a dependency of the numerical solution on the finite element mesh.

Mixed strain/displacement finite elements have been recently proposed as a remedy to the above numerical pathologies. Due to the independent interpolation of strains and displacements these finite element formulations are characterized by an enhanced accuracy in strain localization and crack propagation problems, being at the same time practically mesh independent. For these reasons, mixed finite elements are employed in this work for the out-of-plane assessment of unreinforced masonry structures, being at the same time their first real-scale application. A full-scale experimental campaign of two masonry structures, a stone and a brick one, subjected to shaking-table tests is chosen as reference benchmark. Their structural response under seismic actions is numerically assessed through nonlinear static analysis. The proposed approach is validated through the comparison of the numerical results with the experimental ones, as well as with the results obtained using standard irreducible finite elements.
\end{abstract}

Keywords: Masonry Structures, Out-of-plane loading, Pushover analysis, Cracking, Mixed Finite Elements

*Corresponding author

E-mail addresses: giorgovlachaki@gmail.com (Georgios Vlachakis), miguel.cervera@upc.edu (Miguel Cervera), gbarbat@cimne.upc.edu (Gabriel B. Barbat), savvas.saloustros@upc.edu (Savvas Saloustros) 


\section{Introduction}

Unreinforced masonry structures are one of the oldest structural typologies that are still worldwide inhabited and constitute the majority of the built cultural heritage. However, past seismic events have demonstrated that this type of structures is extremely vulnerable to horizontal loading (e.g. earthquakes of Umbria-Marche 1997, Kashmir 2005, Pisco 2007, L'Aquila 2009, Haiti 2010, Christchurch 2011, Lorca 2011, Emilia Romagna 2012, Nepal 2015, Central Italy 2016, Lesbos 2017, Mexico 2017). According to several postearthquake surveys [1-7], out-of-plane mechanisms are undoubtedly the most crucial among the possible failures of unreinforced masonry structures under horizontal loading. Nevertheless, the out-of-plane behaviour is one of the most complex and yet inadequately addressed topics in the seismic analysis of masonry buildings $[8,9]$. The reason for this is the dependence of the out-of-plane response on several factors, such as the material properties, the quality of the walls, the geometry of the structure, the connections between structural elements and the stiffness of the horizontal diaphragms [10].
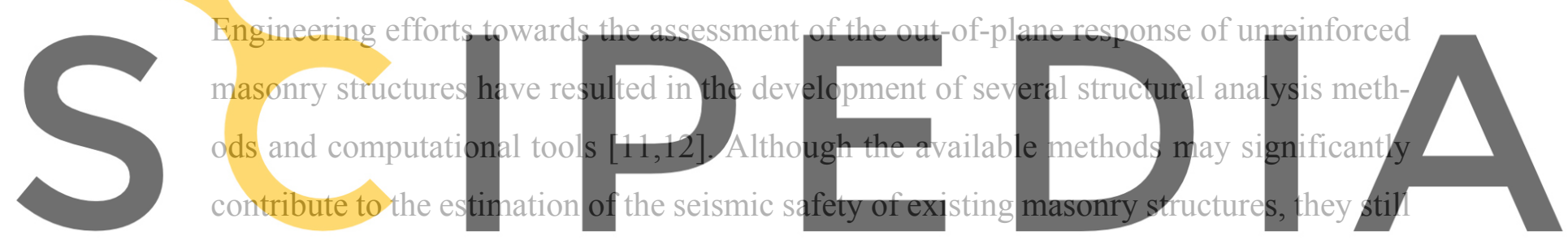

lack the capacity to predict realistic failure mechanisms and to give a reliable estimate Register for free at. httpsf/swww scipedia, Gom to download the version without the watermark

From a methodological point of view, the different assessment techniques can be categorized in two main groups: analytical methods and numerical approaches. The former ones (e.g. $[11,12,22,14-21])$ are based on rigid body mechanics and are characterized by high efficiency and a low number of variables. Nevertheless, the identification and study of the possible collapse mechanisms depends highly on the expertise of the analyst. On the other hand, the advance of computational capabilities and methods in the last decades, has led to the development of a wide variety of numerical approaches [11,23-25]. The selection of an approach upon another is a complex issue, which depends on the field of application, the complexity and scale of the structure and the available resources.

One way to categorize the different numerical strategies is considering the level of the simulation scale. Today, there exist numerical approaches that model the distinct nature of the constituents of masonry (blocks and mortar), while other techniques consider ma- 
sonry as a homogenous material with average properties. Within the first category of $d i$ rect numerical simulations, the most common techniques used for the assessment of the out-of-plane response of masonry structures are the finite element micro-, meso- and multi-scale modelling (e.g. [26-29]), the discrete element method [30-32], and the combined finite-discrete element approach [33]. Although such techniques have proved to be very effective in simulating complex phenomena, the difficulties in obtaining the input parameters (i.e. exact geometry, large number of material and dynamic properties) and, most importantly, their high computational cost hamper their application to large-scale structures.

On the other hand, homogenization procedures are suitable for large-scale applications, as they allow computational modelling at a reasonable cost. A wide variety of homogenization techniques can be found in literature, mainly referring to numerical limit analysis [34-36], discrete macro-modelling [37] and finite element macro-modelling [38].

The finite element macro-modelling approach has been widely used in the last decades[23,24,39], and especially for large-scale structures [40-43]. Its main advantages
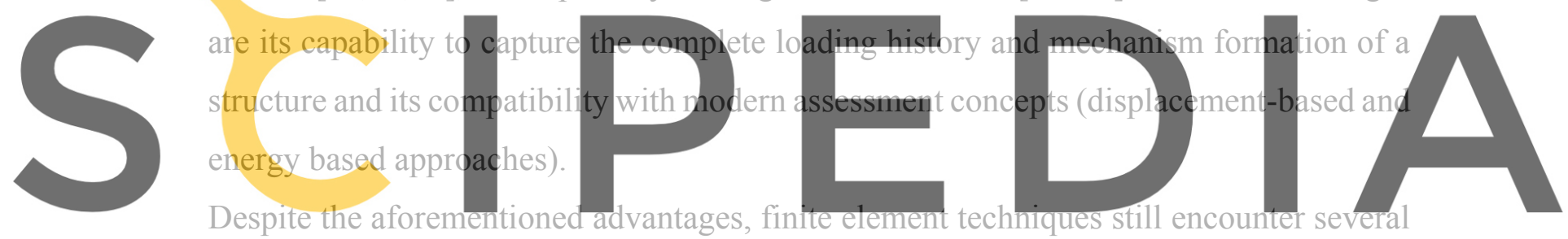

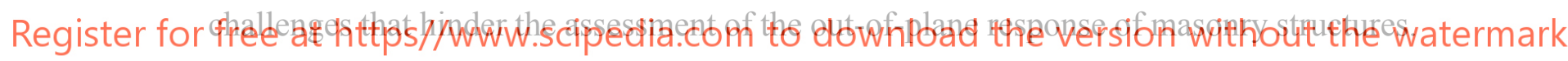

In particular, the reliable mesh-independent simulation of crack propagation in quasi-

brittle materials, such as masonry, is still an open issue within the framework of finite element methods. In the last decades, numerous attempts have been made in order to confront this drawback, adopting mainly two different approaches for the crack simulation: continuous and discontinuous approaches. Within the continuous approach, the failure process is simulated by the degradation of the material at the constitutive level, while within the discontinuous approach, an explicit crack representation is considered and the crack is handled as a geometrical discontinuity. For a general overview of these methods, references [44-47] are recommended.

In the framework of the continuous approach, mixed finite elements have been recently employed as an alternative remedy to the problem of spurious mesh-dependency [48-52]. The main characteristic of the mixed formulation is the independent discrete approxima- 
tion of main mechanical fields of interest. Particularly for the problem of strain localization, mixed finite elements are used to independently consider the strain field of the structure, in addition to the displacements. In this way, an enhanced accuracy for the strains (and consequently also for the stresses) is achieved, which is crucial for the quasi-singular points that lead the fracture and failure processes. This strategy allows mixed formulations to achieve local convergence, resulting in practically mesh-independent results.

The performance of the mixed strain/displacement formulation has been tested under several experimental and theoretical problems both in 2D and 3D including Mode I, Mode II, Mode III and mixed Mode fracture [49-54]. Mixed finite elements have shown to be capable of overcoming many of the challenges related to strain localization problems, providing accurate and practically mesh-independent solutions, without the need of auxiliary crack tracking techniques that are inherent in many discrete and continuous finite element crack approaches [47]. Another important advantage is the possibility to use mixed finite elements with any constitutive law (i.e. plasticity or damage) since their formulation follows the classical local constitutive mechanics framework.
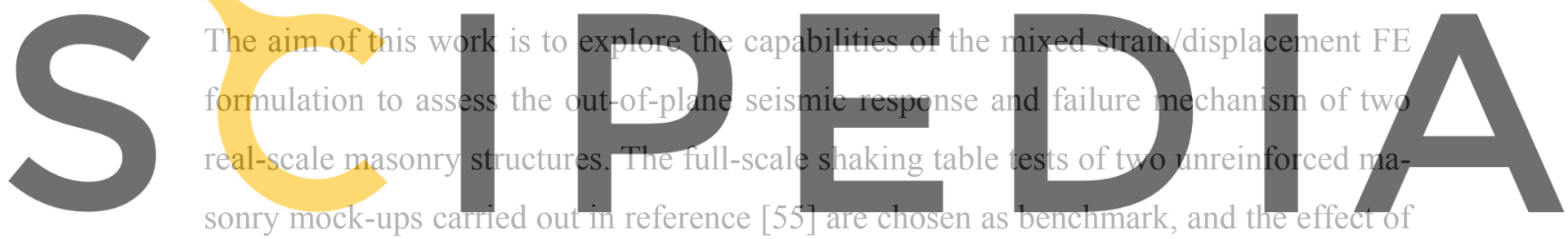

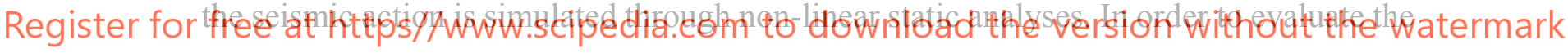
efficiency of the proposed approach, the results are compared with the experimental ones in terms of collapse mechanism and load capacity. The presented analyses are the first application of the mixed finite elements to the simulation of real-scale structures. The enhanced performance of the mixed formulation is validated through their comparison with the results obtained using standard irreducible finite elements.

The outline of the paper is as follows. Section 2 summarizes the mixed finite element formulation and Section 3 outlines the adopted isotropic damage constitutive model. Section 4 presents the numerical simulations of the masonry structures and their comparison with the experimental results and numerical analysis using standard irreducible finite elements. Section 5 includes a comparative study of mesh-dependence using standard and mixed finite elements for in-plane and out-of-plane loading. Finally, the conclusions of the study are summarized in Section 6. 


\section{Mixed Finite Elements}

\subsection{Formulation of the mixed finite elements}

In this section, the matrix formulation of the mixed strain/displacement finite elements is briefly described, while a detailed presentation can be found in reference [53]. The matrix and vector notation adopts Voigt's convention for symmetric tensors.

\subsubsection{Variational form}

In a $3 \mathrm{D}$ problem, the displacements, the strains, the stresses and the body forces at a certain point can be noted as vectors: $\boldsymbol{u}=(u, v, w)^{\boldsymbol{T}}, \boldsymbol{\varepsilon}=\left(\varepsilon_{x}, \varepsilon_{y}, \varepsilon_{z}, \gamma_{x y}, \gamma_{y z}, \gamma_{x z}\right)^{T}, \boldsymbol{\sigma}=$ $\left(\sigma_{x}, \sigma_{y}, \sigma_{z}, \tau_{x y}, \tau_{y z}, \tau_{x z}\right)^{T}$ and $f=\left(f_{x}, f_{y}, f_{z}\right)^{T}$ respectively. The mechanical boundary value problem is defined in terms of these magnitudes, related through the compatibility, equilibrium and constitutive equations, as well as by the boundary conditions. Displacements and strains are locally related through the compatibility equations
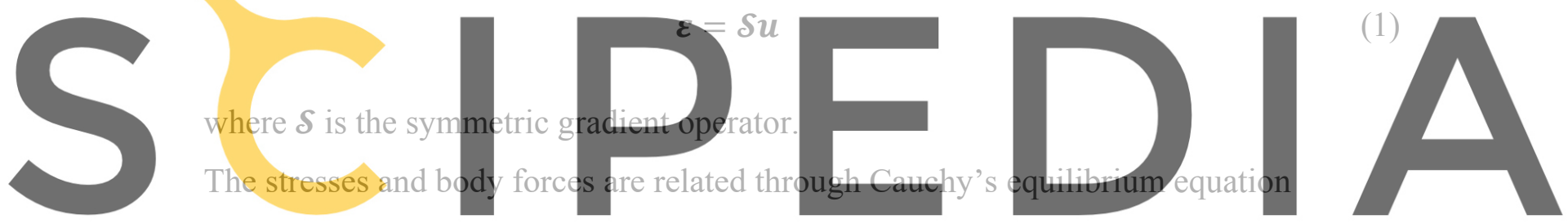

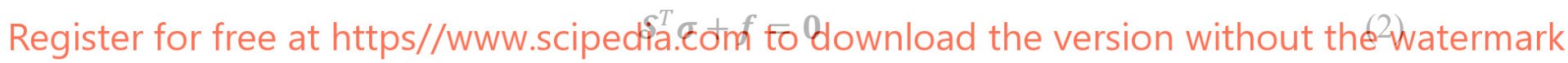

where $\mathcal{S}^{T}$ is the divergence operator. The stresses and the strains are associated through the constitutive equation

$$
\boldsymbol{\sigma}=\boldsymbol{D}_{S} \varepsilon
$$

where $\boldsymbol{D}_{S}$ is the secant constitutive matrix.

In the mixed strain/displacement formulation presented herein, the strains are considered as unknowns in addition to the displacements. Therefore, the strong form can be obtained by pre-multiplying equation (1) with the secant constitutive matrix $\boldsymbol{D}_{S}$ and introducing equation (3) into (2)

$$
-D_{S} \varepsilon+D_{S} \delta u=0
$$




$$
\boldsymbol{S}^{T}\left(\boldsymbol{D}_{S} \boldsymbol{\varepsilon}\right)+\boldsymbol{f}=\mathbf{0}
$$

Equations (4) and (5), together with the proper boundary conditions of the problem compose the strong form of the mixed formulation. These are acting on the boundary $\Gamma$ of the body, either as prescribed displacements $\Gamma_{\mathrm{u}}$ or as prescribed tractions $\Gamma_{\mathrm{t}}$.

Note that further substitution of equation (4) into equation (5) would eliminate the strains as independent unknowns, and yield the standard formulation in terms of displacements only.

The variational form can be obtained in two steps. First, by pre-multiplying equation (4) with an arbitrary virtual strain vector $\delta \boldsymbol{\varepsilon}$ and integrating over the spatial domain $\Omega$, and second, by pre-multiplying equation (5) with an arbitrary virtual displacement $\delta u$ and integrating over the spatial domain $\Omega$. Then, the Divergence Theorem is used in the later equation, while the boundary conditions on $\Gamma_{\mathrm{u}}$ are assumed, for simplicity, $\boldsymbol{u}=\mathbf{0}$. The nontrivial case $\boldsymbol{u}=\overline{\boldsymbol{u}}$ on $\Gamma_{u}$, can be accommodated following standard arguments. Thus,
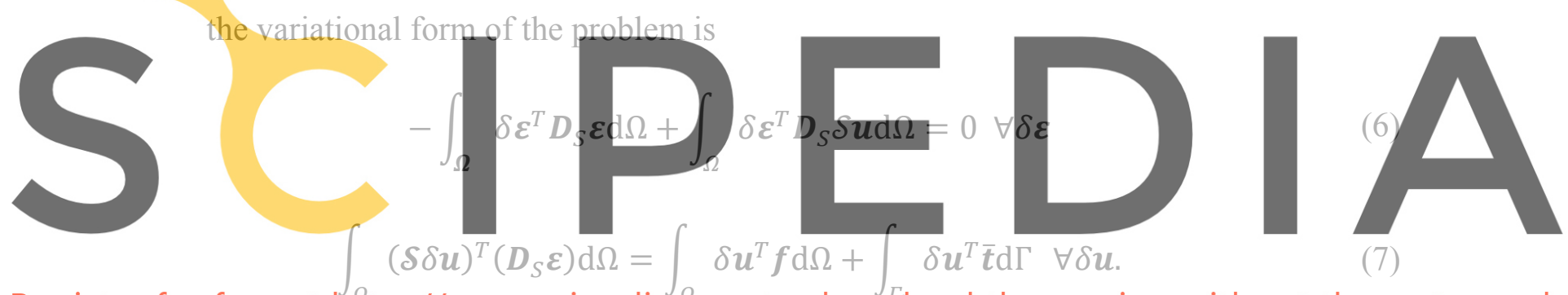

(7)

Register for free at https//www.scipedia.com to down'toad the version without the watermark Summarizing, the weak form of the mixed problem is to find the unknowns $u$ and $\varepsilon$ that verify the system of equations (6)-(7) and the boundary conditions imposed on $\Gamma_{\mathrm{u}}$ and $\Gamma_{\mathrm{t}}$.

\subsubsection{Finite element approximation and stabilization}

In the discretized domain $\left(\Omega=\cup \Omega_{\mathrm{e}}\right)$ of the finite element approximation, displacements $\boldsymbol{u}$ and strains $\boldsymbol{\varepsilon}$ are approximated by

$$
\begin{gathered}
\boldsymbol{u} \cong \widehat{\boldsymbol{u}}=N_{u} U \\
\varepsilon \cong \widehat{\varepsilon}=N_{\varepsilon} E
\end{gathered}
$$

where $\boldsymbol{U}$ and $\boldsymbol{E}$ are the displacements and strains, respectively, at the nodes of the finite element mesh, while $\boldsymbol{N}_{u}$ and $\boldsymbol{N}_{\varepsilon}$ are the interpolation functions adopted in the finite elements. 
If equal interpolations are considered for the strains and the displacements in equation (8) and (9) the solvability and the stability of the problem is not verified since the Inf-Sup condition [56] is not satisfied. Therefore, a stabilization technique is used in order to circumvent this problem, and ensure the necessary stability via the Orthogonal Subscales Method [48].

Specifically, this is achieved by substituting the approximated strains with the following form instead of using equation (9)

$$
\boldsymbol{\varepsilon} \cong \widehat{\boldsymbol{\varepsilon}}=\boldsymbol{N}_{\varepsilon} \boldsymbol{E}+\tau_{\varepsilon}\left(\boldsymbol{B}_{u} \boldsymbol{U}-\boldsymbol{N}_{\boldsymbol{\varepsilon}} \boldsymbol{E}\right)=\left(1-\tau_{\varepsilon}\right) \boldsymbol{N}_{\varepsilon} \boldsymbol{E}+\tau_{\varepsilon} \boldsymbol{B}_{u} \boldsymbol{U}
$$

where $\boldsymbol{B}_{u}$ is defined as $\boldsymbol{B}_{u}=\boldsymbol{S} \boldsymbol{N}_{u}$, and $\tau_{\varepsilon}$ is a stabilization parameter that ranges from 0 to 1 . Note that this stabilization technique is fully consistent, as the stabilization form consists of the residual of equation (1). This means that the stabilization term $\left(\boldsymbol{B}_{u} \boldsymbol{U}-\boldsymbol{N}_{\varepsilon} \boldsymbol{E}\right)$ tends to zero on mesh refinement. Observe that for $\tau_{\varepsilon}=0$ the stabilization effect is lost, while for $\tau_{\varepsilon}=1$ the standard irreducible formulation is recovered.

Intermediate values of the stabilization parameter represent alternative blending between
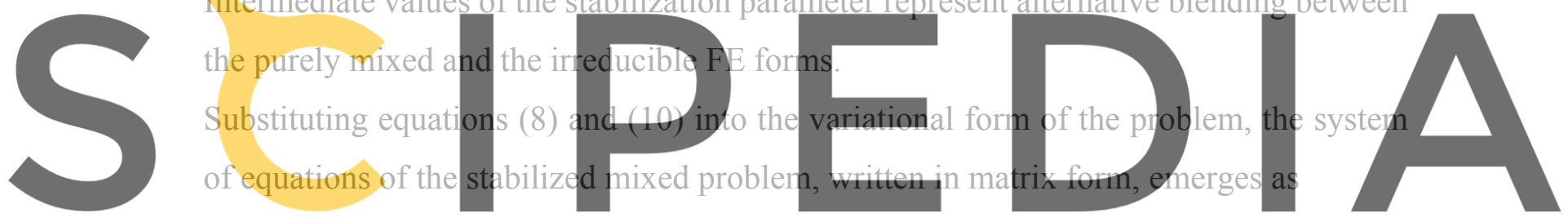

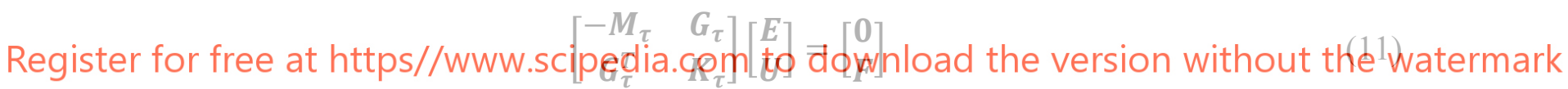
such that

$$
\begin{gathered}
\boldsymbol{M}_{\boldsymbol{\tau}}=\left(1-\tau_{\varepsilon}\right) \int_{\Omega} \boldsymbol{N}_{\varepsilon}^{T} \boldsymbol{D}_{S} \boldsymbol{N}_{\varepsilon} \mathrm{d} \Omega \\
\boldsymbol{G}_{\boldsymbol{\tau}}=\left(1-\tau_{\varepsilon}\right) \int_{\Omega} \boldsymbol{N}_{\varepsilon}^{T} \boldsymbol{D}_{S} \boldsymbol{B}_{\boldsymbol{u}} \mathrm{d} \Omega \\
\boldsymbol{K}_{\boldsymbol{\tau}}=\tau_{\varepsilon} \int_{\Omega} \boldsymbol{B}_{\boldsymbol{u}}^{T} \boldsymbol{D}_{S} \boldsymbol{B}_{\boldsymbol{u}} \mathrm{d} \Omega \\
\boldsymbol{F}=\int_{\Omega} \boldsymbol{N}_{\boldsymbol{u}}^{T} \mathbf{f} \mathrm{d} \Omega+\int_{\Gamma_{\boldsymbol{t}}} \boldsymbol{N}_{\boldsymbol{u}}^{T} \overline{\mathrm{t}} \mathrm{d} \Gamma
\end{gathered}
$$

where $[\boldsymbol{E} \boldsymbol{U}]^{T}$ are the strains and displacements at the nodes of the mesh, the unknowns of the algebraic problem to be solved. 


\section{Continuum damage model}

An isotropic continuum damage model is adopted [57] for modelling of the non-linear behaviour of the material.

In this model, an internal damage index $d$ describes at constitutive level the material degradation. This scalar-type variable ranges from 0 for an intact material to 1 for a completely damaged one. The constitutive equation is described as

$$
\boldsymbol{\sigma}=\boldsymbol{D}_{S} \boldsymbol{\varepsilon}=(1-d) \boldsymbol{D}_{0} \boldsymbol{\varepsilon}=(1-d) \overline{\boldsymbol{\sigma}}
$$

where the effective stress $\overline{\boldsymbol{\sigma}}$ is introduced as $\overline{\boldsymbol{\sigma}}=\boldsymbol{D}_{0} \boldsymbol{\varepsilon}$, corresponding to the hypothesis of strain equivalence [58].

\section{The damage criterion, $\mathrm{F}$, is}

$$
\mathrm{F}\left(\sigma_{e q}, r\right)=\sigma_{e q}(\bar{\sigma})-r \leq 0
$$

where $\sigma_{e q}(\bar{\sigma})$ is the equivalent effective stress defining the adopted failure surface, and $r$
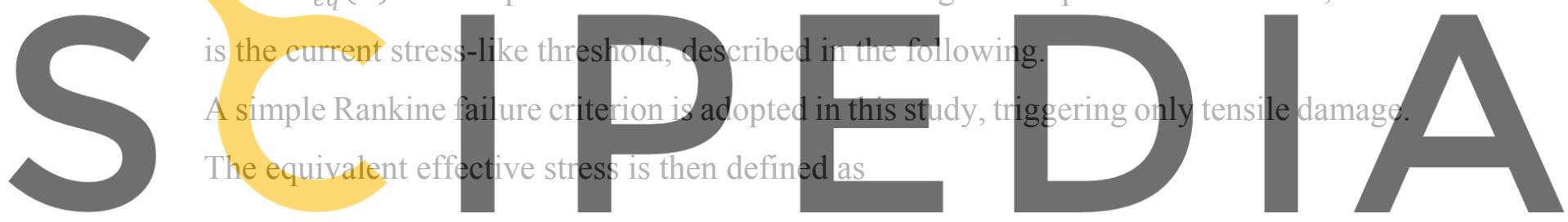

Register for free at https//www.scipedid.com to download the version without the watermark

where $\bar{\sigma}_{1}$ is the maximum principal effective stress, while \langle\rangle stands for the Macaulay brackets $(\langle x\rangle=x$ if $x \geq 0,\langle x\rangle=0$ if $x<0)$.

The initial value of the stress-like damage threshold $r$ is equal to the tensile strength of the material $r_{0}=f_{t}$, while it is explicitly updated at every step of the analysis $\hat{t}$ in order to consider the loading history and guarantee the irreversibility of damage

$$
r=\max \left(r_{0}, \max \sigma_{e q}(\hat{t})\right) \quad \hat{t} \in[0, t]
$$

An exponential softening law is adopted for describing the evolution of the damage index

$$
d=d(r)=1-\frac{r_{0}}{r} \exp \left(-2 H_{s} \frac{r-r_{0}}{r_{0}}\right)
$$


where $H_{s} \geq 0$ is the discrete softening parameter, taking into account the fracture energy of the material $G_{f}$ and the characteristic finite element width $b$, ensuring mesh-size objective results according to the crack-band theory [59]. It is defined as

$$
H_{s}=\frac{\bar{H}_{s} b}{1-\bar{H}_{s} b}
$$

where $\bar{H}_{s}$ is the inverse of the material length $\mathcal{L}$

$$
\bar{H}_{s}^{-1}=\mathcal{L}=\frac{2 E G_{f}}{\left(f_{t}\right)^{2}}
$$

\section{Numerical simulation of two masonry structures}

In this section, the mixed finite element formulation is applied for the first time to the analysis of two real-scale masonry structures, which were tested in an experimental campaign by Candeias et al. [55].

The experimental campaign was carried in the National Laboratory of Civil Engineering,
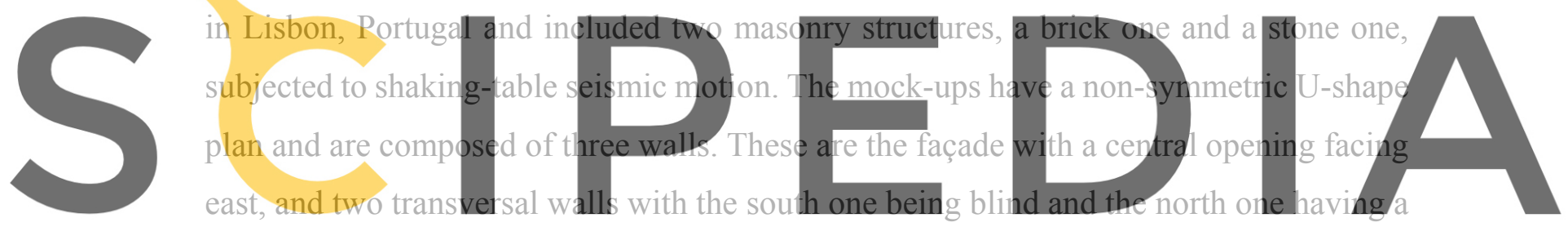

window opening. A lime-based mortar was used for the construction for both mock-ups,

Register for free at https //www.scipedia.com to download the version without the watermark while cement was added to the mortar used at the base, to ensure the connection of the

structures with the shaking tabie. The detailed geometry of the two mock-ups is presented in Figure 1a,b, while the reader is referred to the original work for more information on the geometrical characteristics [55]. Both mock-ups were subjected to a sequence of unidirectional seismic loadings with increased Peak Ground Acceleration (PGA) (referred hereafter as TEST01-08) up to collapse, with a direction perpendicular to the façade.

Figure 2 presents the damage evolution at the end of some test sequences. Significant torsional effects, due to the asymmetric configuration of the openings, characterized the dynamic response of both structures. Concerning the brick structure, damage started developing at TEST05 and was already important at TEST07. The failure mechanism involved the out-of-plane collapse of the gable, together with the in-plane failure of the north return wall (both spandrel and piers). Additionally, the northern part of the gable experienced a local collapse. In the case of the stone structure, cracking initiated during the first two imposed seismic ground motion records (TEST01-02), and it consolidated 
during TEST03 and TEST05. The developed collapse mechanism involved a portion of the south part of the façade, the gable, the northeast corner, the spandrel of the window and the northwest pier. Especially for the stone structure, the high unit-to-structure size ratio and the big stones used as lintels played a decisive role to its structural behaviour, affecting both the local crack patterns and the developed collapse mechanisms. Finally, brick and stone structures experienced large displacements of $136.5 \mathrm{~mm}$ and $218.5 \mathrm{~mm}$, respectively at the top of the gable, with a dominating rocking response after the failure mechanisms were formed.
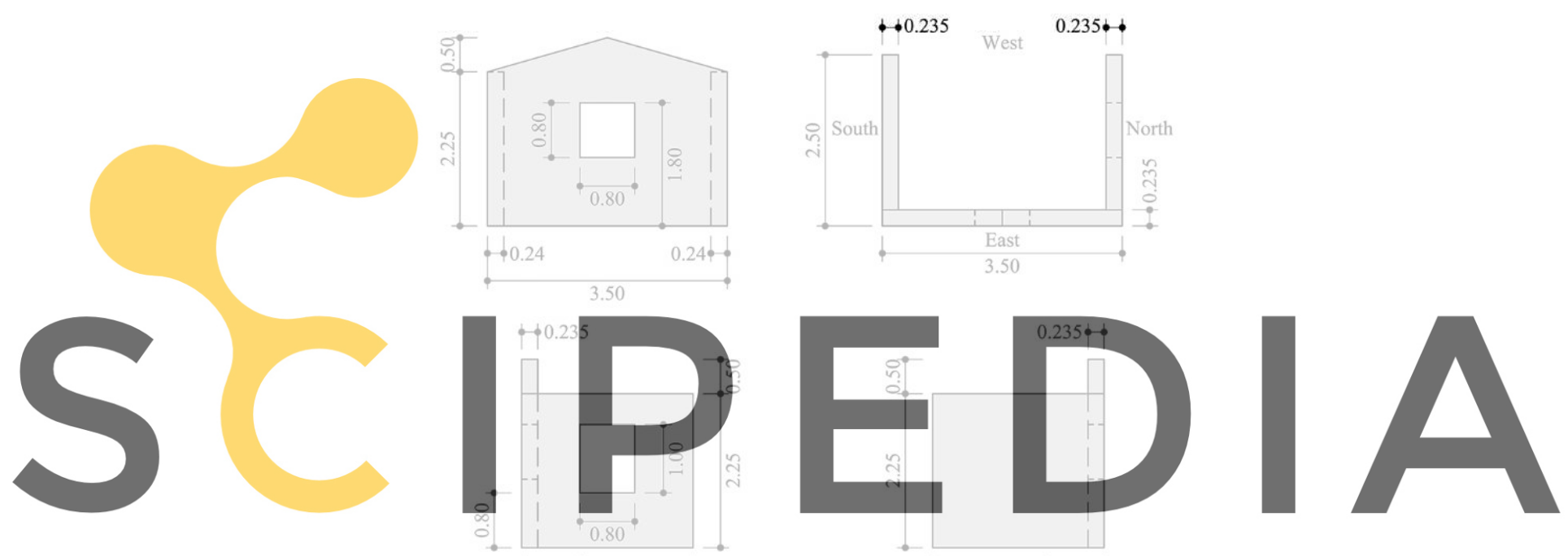

Register for free at https//wwwi.scipedia.çom to downloạd the verșion without the watermark (a)
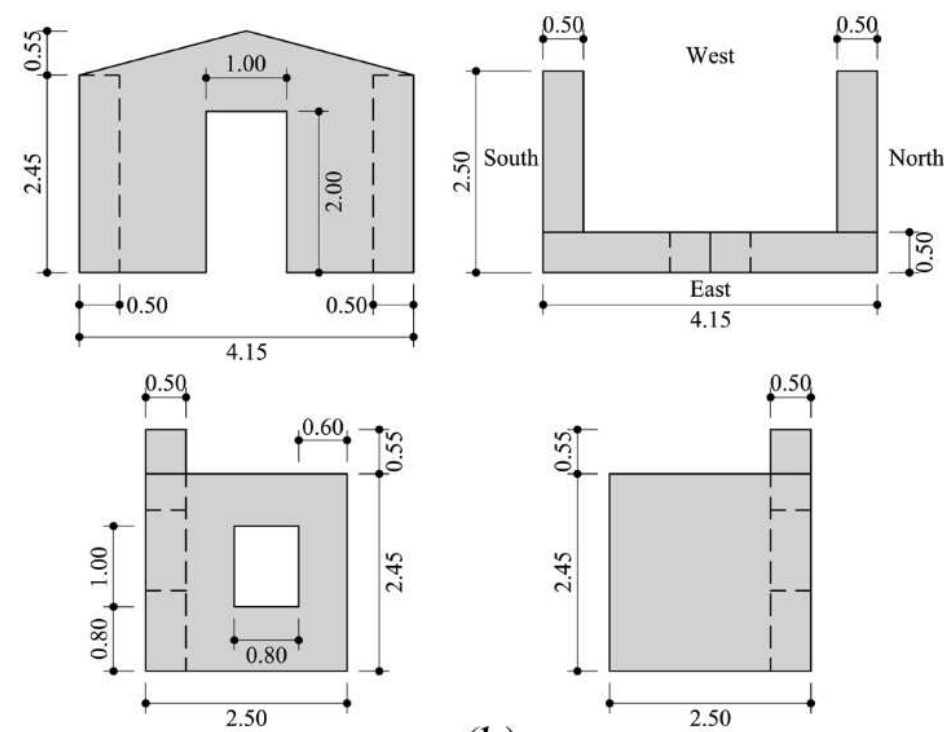

(b)

Figure 1 Geometry of (a) the brick structure and (b) the stone structure (Units in meters. Figure adapted from Candeias et al. [55]). 

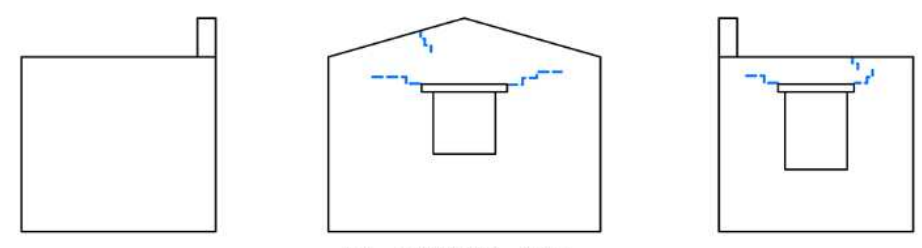

After TEST06 - $0.56 \mathrm{~g}$
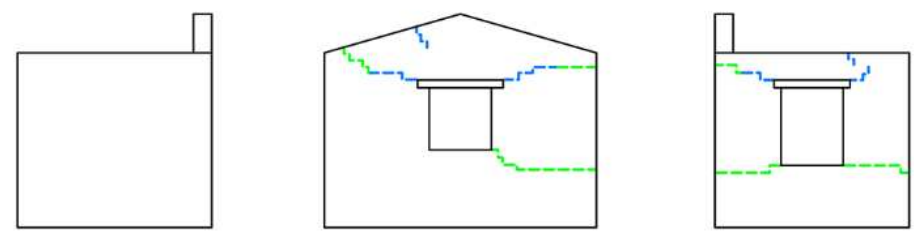

After TEST07 - $0.84 \mathrm{~g}$
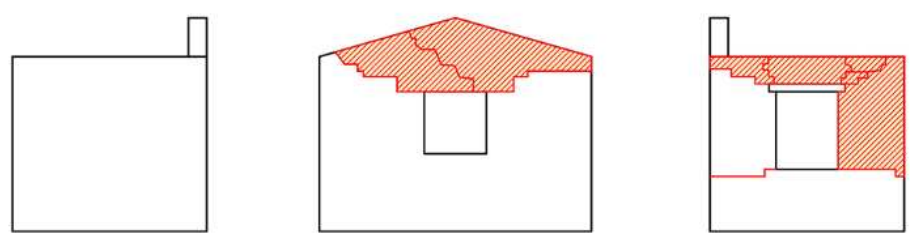

After TEST08 - $1.27 \mathrm{~g}$

(a)
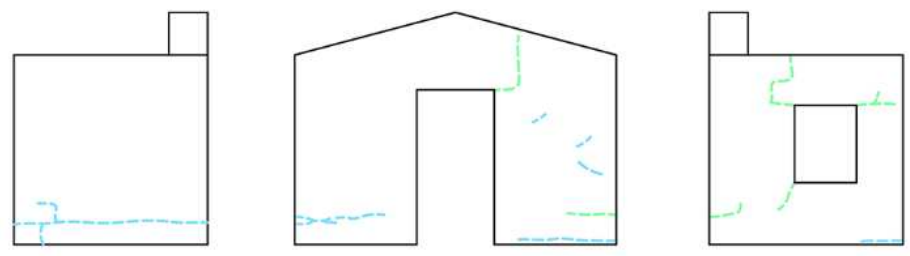

After TEST03 - $0.66 \mathrm{~g}$
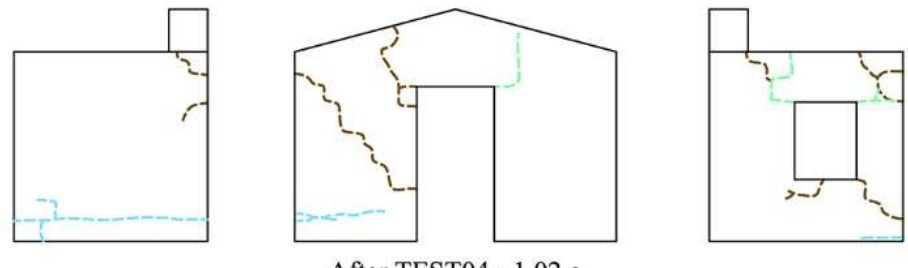

After TEST04 - $1.02 \mathrm{~g}$
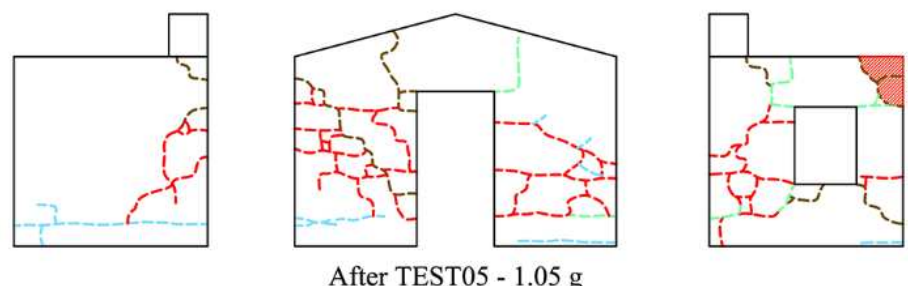

(b)

Figure 2 Damage evolution and collapse mechanism for (a) the brick structure, and (b) the stone structure (Figure adapted from Candeias et al. [55]). 
The aforementioned experimental campaign is simulated in this work with the mixed strain/displacement finite element formulation. The numerical models aim to capture the structural response of the two mock-ups by means of nonlinear equivalent static analysis, while the nonlinear dynamic analysis of the tests will be addressed in a future work. Despite the known limitations of pushover analysis, such as the not consideration of the inertial phenomena and the cyclic nature of earthquake actions, it is widely regarded as a computationally efficient alternative to nonlinear dynamic analysis. For this reason, pushover analysis is included in several standards [60-62] and is commonly used for the estimation of the seismic response of masonry structures (e.g. [41,43,63-65]).

In the following, the load is applied perpendicular to the façade in both positive $+\mathrm{X}$ (referred to as the "Pulling" case hereafter) and negative -X (referred to as the "Pushing" case hereafter) directions (see Figure 3 for the $+\mathrm{X}$ direction). The effect of the seismic action is simulated as an "equivalent" mass-proportional horizontal body force, applied after the application of the self-weight. The use of an isotropic damage model, described in Section 3 is justified by the monotonic nature of the applied loading and the absence of reported brick or stone crushing. The extension of this model to consider orthotropic induced damage and irreversible deformations in the case of cyclic and dynamic loading is feasible as described in Barbat et al. [54] and Saloustros et al. [66].
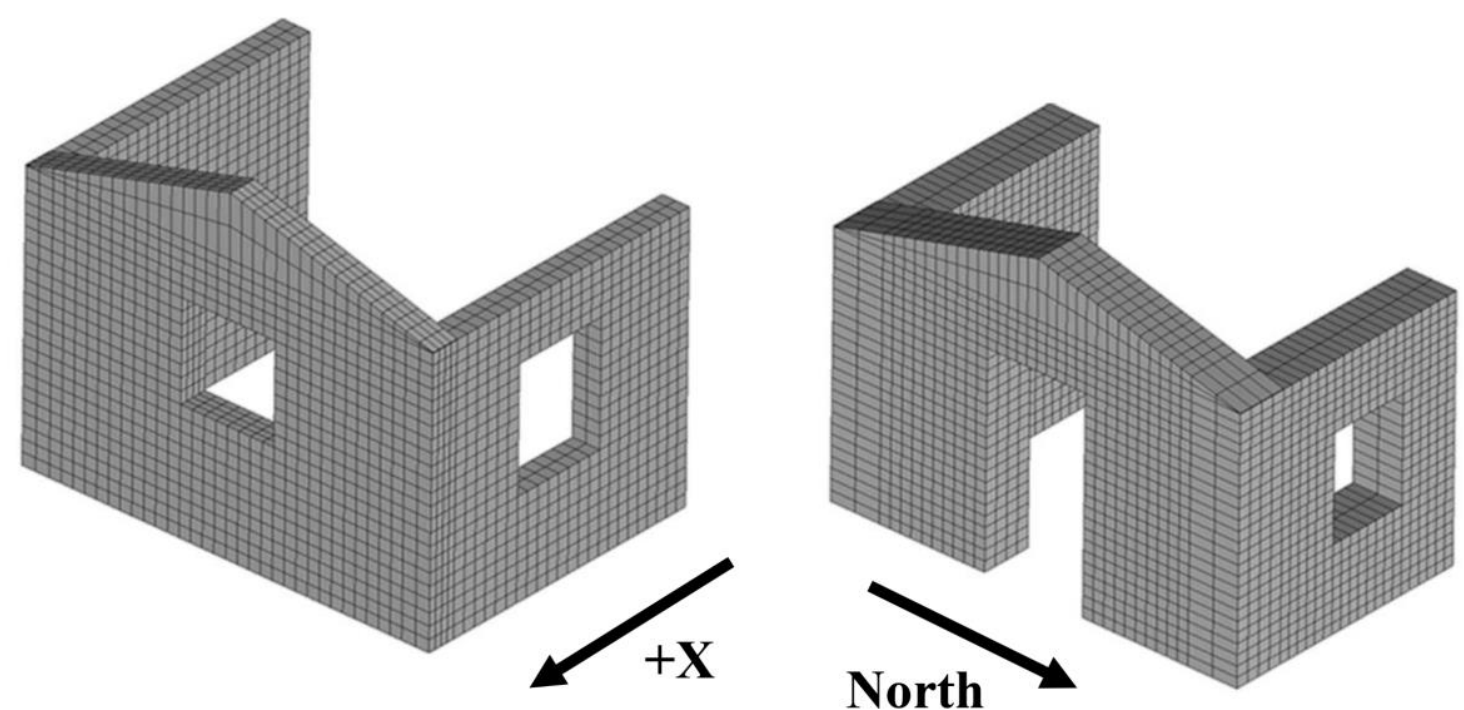

Figure 3 Adopted finite element meshes for the brick (left) and the stone (right) structures. 
The material properties used in the simulations (shown in Table 1) are the ones provided by the experimental campaign [55], and were obtained by testing six wallets for each building, in vertical and diagonal compression. It should be noted that the fracture energy was not given by the experiment and values are adopted according to Lourenço [67], as in Chácara et al. [68] and Cannizzaro \& Lourenço [69]. The calibration of the value of the fracture energy according to the experimental results using a reverse engineering approach is out of the scope of this work. The investigation of the capacity of the mixed FE formulation to predict the out-of-plane behaviour of masonry structures and to the correctly identify of the collapse mechanisms is carried out using typical values of fracture energy that are commonly adopted when experimental results are not available.

Table 1 Mechanical Parameters for the brick and stone structures

\begin{tabular}{cccccc}
\hline & Young's & Specific & & Tensile & Tensile \\
Modulus & Mass & Poisson's & Ratio & Strength \\
$(\mathrm{GPa})$ & $\left(\mathrm{kg} / \mathrm{m}^{3}\right)$ & Rature & $\begin{array}{c}\text { Energy } \\
(\mathrm{N} / \mathrm{m})\end{array}$ \\
\hline \hline Brick & 5.17 & 1890 & 0.2 & 0.102 & 12 \\
Stone & 2.08 & 2360 & & 0.224 & 48 \\
\hline
\end{tabular}

3D hexahedra solid elements with linear/linear interpolations are used for the discretization of the structure, while the integration points are set at the nodes of the elements. A structured mesh is constructed consisting of approximately $0.1 \times 0.1 \mathrm{~m}^{2}$ elements over the plane of the walls, while 4 and 2 elements across their thickness are used in the façade and the return walls, respectively. This mesh size has been chosen after performing the proper sensitivity analysis of the results with respect to mesh refinement (see [70]). The difference in the number of elements per thickness of the façade and return walls is due to the fact that the first is subjected mainly to out-of-plane bending, which results in stresses and strains variation across the thickness. On the contrary, the two return walls are subjected mainly to in-plane loading that does not produce significant stresses and strains variation across the thickness of the wall. The final models are illustrated in Figure 3, composed of 5100 and 4712 elements for the brick and the stone structure, respectively. A stabilization parameter $\tau_{\varepsilon}=0.1$ is used in all the simulations. Finally, it should be noted that in the pushing cases of the analyses (-X), the first two layers of elements at the 
base are set to have a linear elastic behaviour. This choice intends to replicate the use of cement mortar at the base of the mock-ups, which aimed to prevent a possible sliding between the structure and the shake table [55].

Calculations are performed using the finite element program COMET [71,72], while the pre- and post-processing is done using GiD [73] both developed at CIMNE, Barcelona (International Centre for Numerical Methods in Engineering). The analyses are performed using an arc-length strategy in order to capture any possible snap-back response. Convergence of a load step increment is attained when the ratio between the norm of residual forces and the norm of the total external forces is lower than $10^{-2}(1 \%)$.

\subsection{Brick Structure}

\subsubsection{Pushover analysis of the brick structure}

Figure 4 presents the base shear force against the horizontal displacement at the top of the gable wall curve for the Pushing $(-X)$ and the Pulling cases $(+X)$. The structure presents a higher capacity when loaded towards $-\mathrm{X}$ direction (Pushing) than towards $+\mathrm{X}$ (Pulling). This is due to the beneficial effect of the return walls, which act as buttresses restraining the rotation of the façade during its pushing.

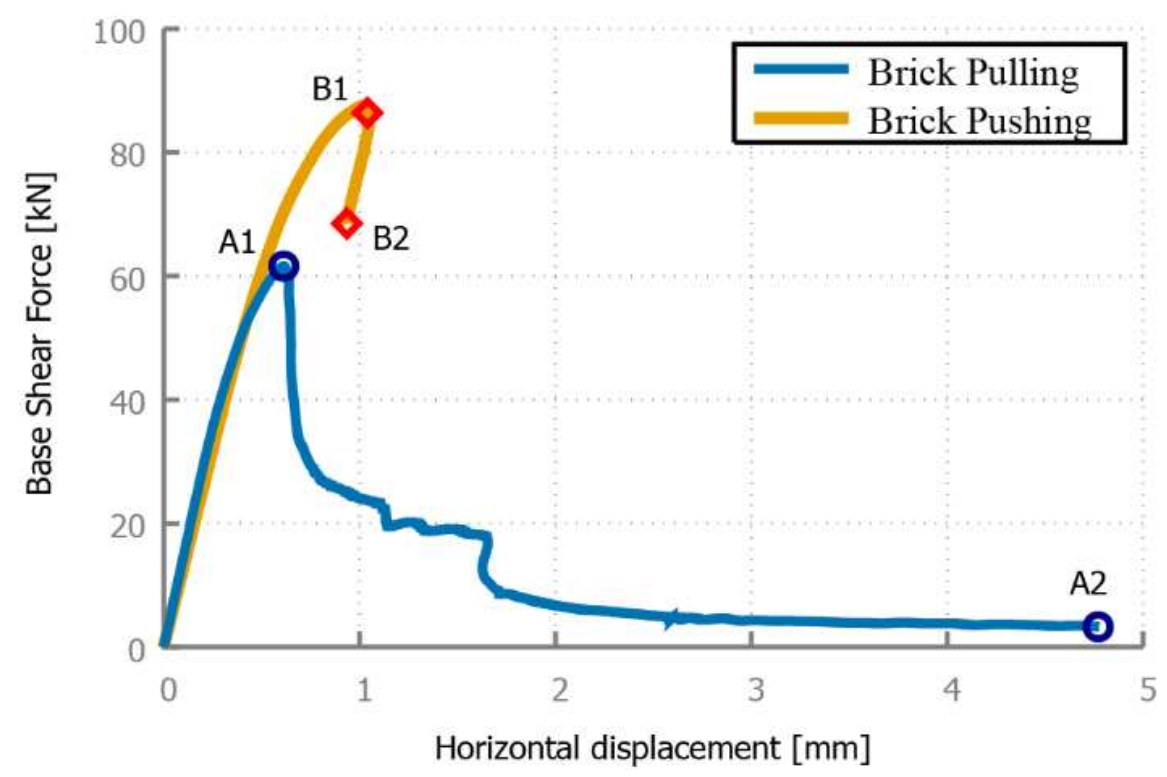

Figure 4 Base shear force against horizontal displacement at the top of the gable of the brick structure for both the Pulling $(+X)$ and Pushing $(-X)$ cases.

Figures $5 \mathrm{a}$ and $5 \mathrm{~b}$ illustrate the strain localization process occurring during the Pulling $(+X)$ of the brick structure at the peak load and at the end of the analysis, respectively. 
Initially, the structure responds almost elastically until reaching a value of the base shear of around $40 \mathrm{kN}$. At that point, damage develops and stiffness starts to decrease, until a peak load of around $60 \mathrm{kN}$. Figure 5a shows the open cracks (for elements with $\varepsilon_{\max } \geq$ $1.9710^{-5}$ ) at this stage of the analysis, through the contour of the maximum principal strain. At the façade, strain is localized at the west side of its base, which is caused by its vertical bending. A diffused strain field with high values also appears at the gable of the façade, without however showing any localization at this stage of the analysis. The outof-plane loading of the façade results in the initiation of two cracks at the connections with the return walls, especially at the top part. Regarding the return walls, both are slightly damaged at the west side of their base, due to their in-plane bending. Contrary to the south wall, the presence of a window opening in the north wall makes it more susceptible to damage. More specifically, diagonal shear cracks appear at the two corners of the window, whereas cracking exists at the top east side of the spandrel.

After reaching the peak load, the structure shows a very brittle response with significant loss of load capacity. This is due to the extension of the damage at the north return wall resulting in local collapse mechanisms. More specifically, the spandrel is the first completely damaged element, with two cracks propagating at its two sides. At this point, the structure presents some residual strength, while the façade is bending horizontally as a cantilever due to the loss of its constraint at the north side. The northeast corner of the structure is weakly supported, as it has lost in succession the resistance of the spandrel, of the east pier in the north return wall (due to the diagonal crack) and finally, of its base, due to the flexural crack at the base of the façade. As a result, a second significant loss of load capacity appears for a displacement of $1.65 \mathrm{~mm}$, which corresponds to the development of a diagonal crack that connects the north lower and south upper corners of the façade, crossing the window (Figure 5b). The complete development of this crack marks the formation of the collapse mechanism of the façade, and therefore, the top of the gable presents large displacements with very low resistance, until the crack propagates across the thickness of the façade and equilibrium is lost.

In the end of the analysis, the collapse mechanism of the structure is composed by three macro-elements. Namely the west pier of the north return wall, the spandrel of the north wall and the northeast corner, which includes the east pier of the north return wall and the upper north part of the façade (Figure 5b). 


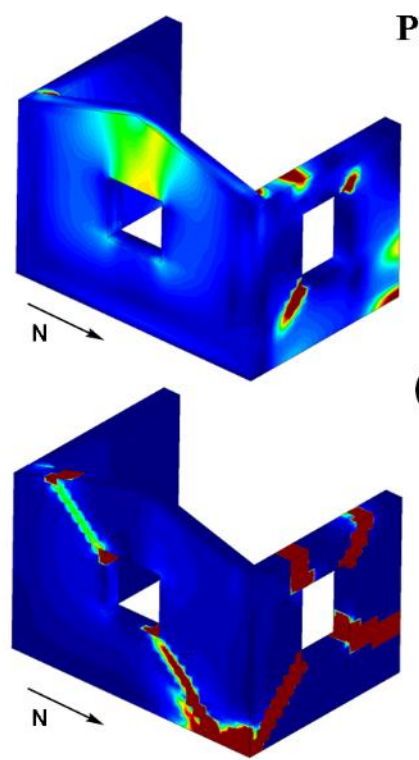

Pulling

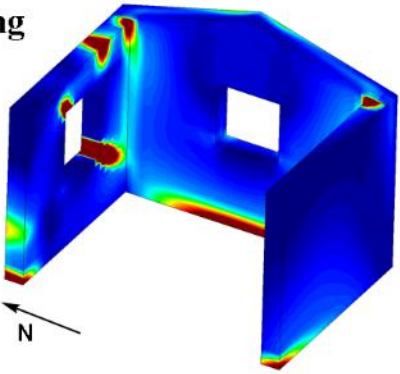

(a)

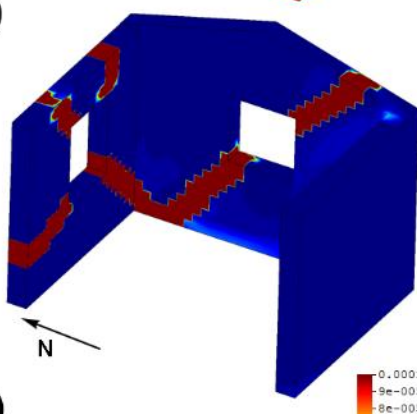

(b)

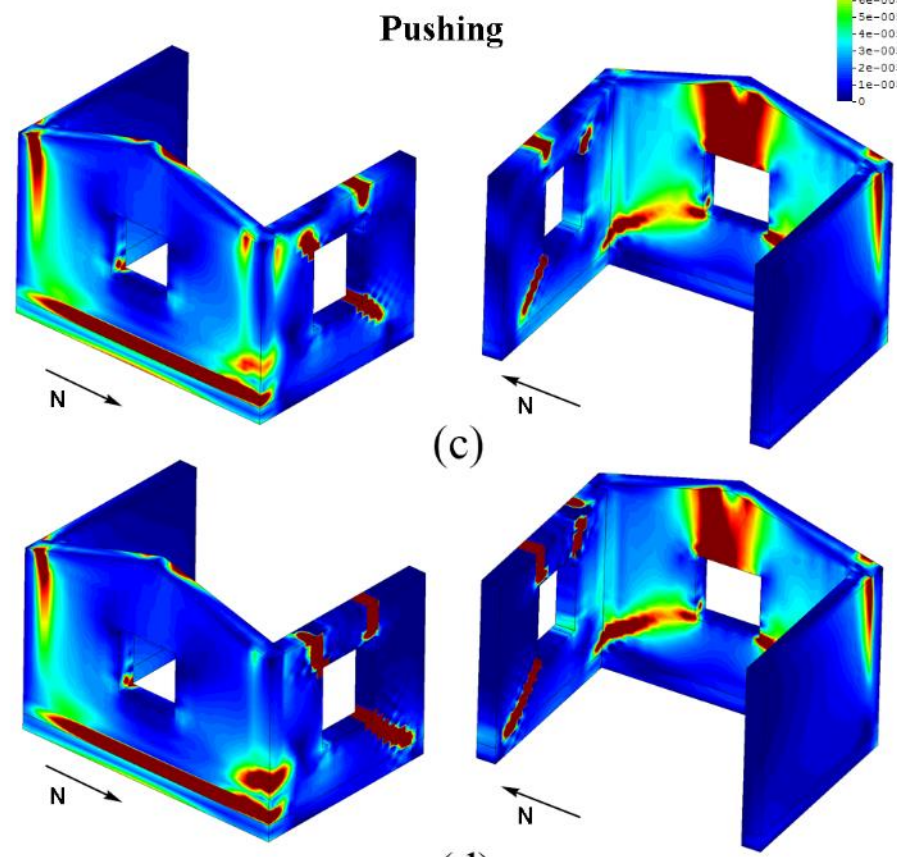

(d)

Figure 5 Contour of the maximum principal strains for the brick structure at different instances corresponding to the points of Figure 4: (a) A1 Pulling (+X), (b) A2 Pulling (+X), (c) B1 Pushing (-X) and (d) B2 Pushing (-X).

Regarding the Pushing (-X) case, the structure responds almost elastically up to a base shear force of $60 \mathrm{kN}$. From that stage of the analysis until the maximum capacity of 90 $\mathrm{kN}$ is reached, cracking develops simultaneously in several parts of the structure, as shown in Figure 5c. More specifically, the out-of-plane bending of the façade results in the first crack at its east base. As this crack develops, the return walls provide the only 
restriction to the out-of-plane movement of the facade. This beneficial action of the return walls changes the cracking pattern compared to the pulling case and results in vertical cracking at the gable above the window and at the corner connections of the façade with the return walls. Diagonal cracks also appear at the lower corners of the window. At the same time, significant in-plane damage occurs at the north return wall, due to the weakness introduced by the window. In particular, cracks at the both sides of the spandrel interrupt its connection with the piers, while a diagonal shear crack develops at the west lower corner of the window.

After the peak load, the propagation of the cracks at the spandrel and the west pier of the north wall produce a local failure (Figure $5 \mathrm{~d}$ ). The formation of this local collapse mechanism results in the loss of the equilibrium and marks the end of the analysis. Consequently, any further response at the softening region is not captured, due to lack of convergence of the equilibrium iterations.

\subsubsection{Comparison with Experimental Results}

The performance of the proposed approach is assessed in the following in terms of collapse mechanism and load capacity, through the comparison of the obtained numerical results with the results of the experimental campaign. Note that such a comparison is not straightforward for several reasons. First, as identified by [74], the characteristics of the ground motions, which are not considered in pushover analyses, may significantly influence the out-of-plane behaviour of the specimen. Second, the shaking table test provokes cyclic loading with dynamic effects taking place, while the non-linear static analysis is intrinsically monotonic and neglects inertial or damping effects. Third, the experimental procedure included a sequence of 8 steadily increasing excitations (TEST01-08) until the collapse of the structure. Therefore, damage was accumulated at every TEST, while the numerical analysis involves only one monotonic excitation until the loss of equilibrium. In the following, the presentation of the experimental collapse mechanism is followed by its comparison with the numerical results.

The main failure mechanism of the brick mock-up involved a part of the gable wall and a big portion of the north return wall (Figure 2a), while a secondary local failure mechanism involved a part of the gable. More specifically, the main failure mechanism was already developed during the TEST07 as can be seen in Figure 2a, and involved four macro-elements: the northwest pier of the north return wall, the spandrel of the north return wall, the northeast corner and finally the gable of the façade. Consequently, during 
TEST08, the aforementioned mechanism was already formed and presented a rocking response. This rocking response, which was governed by torsional effects, was more intense at the north side, and therefore caused the formation of the secondary mechanism at the north part of the gable.

(a)
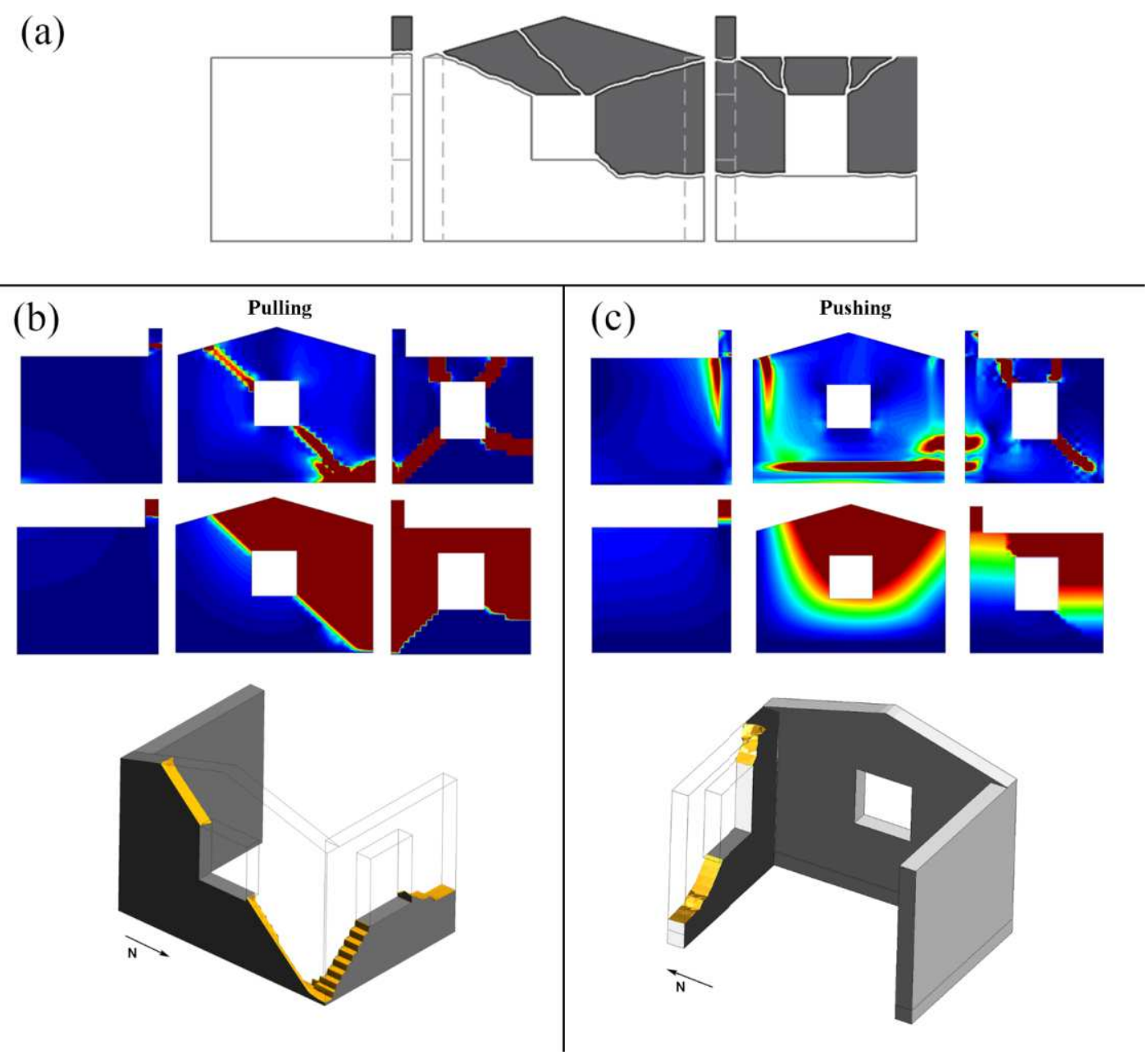

Figure 6 Comparison of the experimental collapse mechanism of the stone structure with the numerical one. (a) The experimental collapse mechanism (Figure adapted from Mendes et al. [76]), (b) maximum principal strains (top), displacements (middle) contour and crack surface (bottom) at point A2 of Figure 4, and (c) maximum principal strains (top), displacements contour (middle) and crack surface (bottom) at point B2 of Figure 4.

The mock-up appeared to be more vulnerable in the outward direction of the façade $(+X)$, both before and after the complete formation of the mechanism [55], which is in agreement with the results of the proposed model, as discussed previously and shown in Figure 5. Figure 6 presents a comparison of the experimental mechanism [75] (shown in Figure 
6a) and the results obtained for the pulling and pushing cases, respectively, with the proposed approach (shown in Figure 6b,c). The crack surface, shown in Figure 6, represents the location of the predominant cracks that divide the structure in different macroelements. This contour is obtained by plotting the isosurface of the displacements for a selected at each case displacement threshold. In general, it can be appreciated that the obtained collapse mechanism is in good agreement with the experimental results. Regarding the north return wall, both analyses towards the $\pm X$ directions predict correctly the inplane collapse mechanism and crack pattern. The numerical models capture also the outof-plane failure of the top part of the façade and the northeast corner, with some differences that are discussed in the following.

Firstly, the numerical models do not predict the diagonal crack at the northern part above the window in the façade (see Figure 6a), which resulted in the collapse of the gable during the experiment. This cracking might have been provoked in the experiment by the presence of a wooden lintel above the window, which has not been considered in the numerical analyses. Secondly, there is a difference of the crack propagation at the northeast corner. The experimental structure develops a horizontal crack following the mortar joints and connecting the low corners of the two windows of the façade and the north wall, while the numerical model develops two diagonal cracks starting at the corners of the windows and joining at the lowest point of the corner. On the one hand, this difference may be due to the orthotropic behaviour of the brick masonry, which is not considered by the adopted isotropic elastic and damage models. In cases where the distinct linear and nonlinear directional properties of masonry are known, orthotropic damage models can be used to simulate the distinct response of masonry vertical and parallel to the mortar joints (e.g. [76,77]). On the other hand, the numerical results for the Pushing case (-X) could predict this horizontal crack (see Figure 5c,d). This implies that the experimentally obtained collapse mechanism is the result of the cumulative damage during the cyclic loading of the mock-up.

According to Candeias et al. [55], the collapse mechanism of the brick structure started to form at TEST05 and was completed at TEST07. The values of the base shear corresponding to the PGAs' of these two experimental tests have been plotted together with the pushover curves in Figure 7. The graphs show a good correlation between the experimental and the numerical results for the Pulling case, with a collapse mechanism similar 
to the experimental one. For this case, the initiation of the collapse mechanism coincides with the beginning of the stiffness degradation and its completion with the peak load.

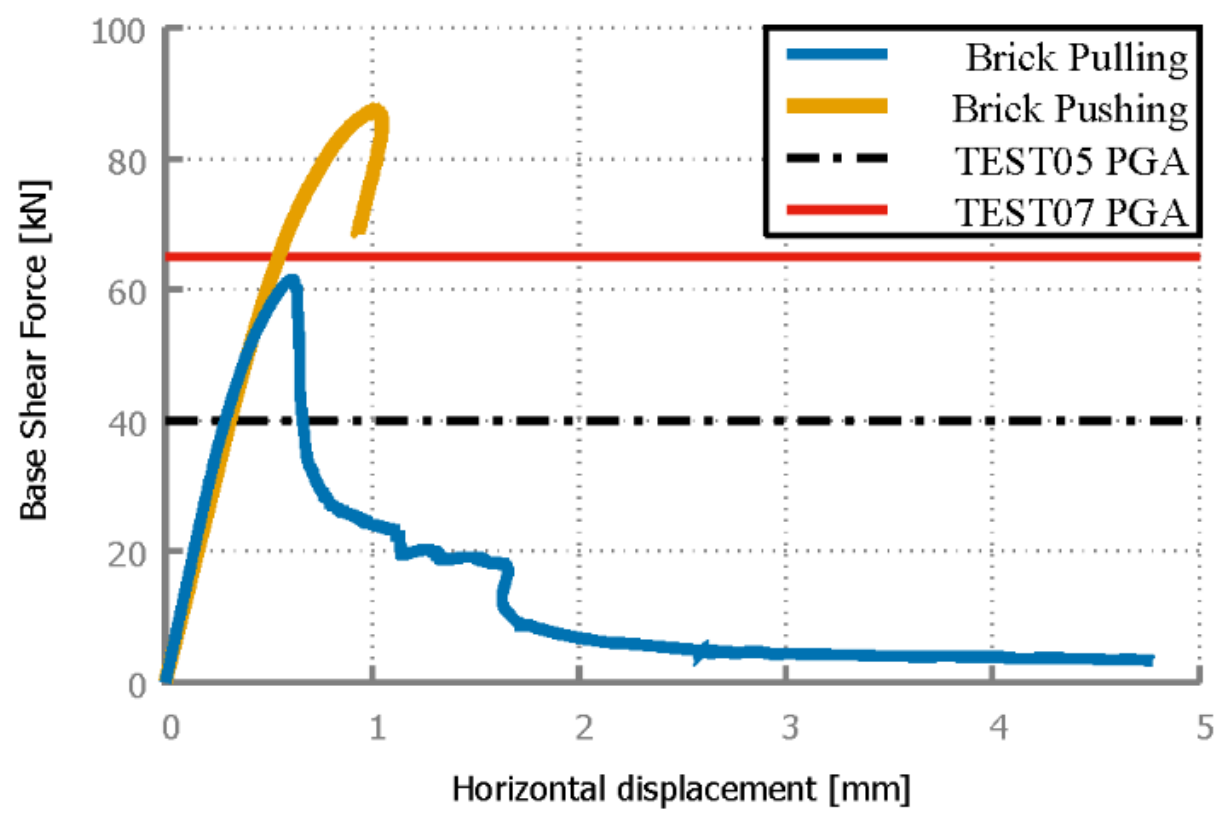

Figure 7 Comparison of base shear force against horizontal displacement at the top of the gable of the brick structure with the base shear values corresponding to the experimental PGAs of TEST05 and TEST07.

\subsubsection{Comparison with Standard Finite Elements}

This subsection investigates the enhanced accuracy of the proposed mixed formulation by comparing the results with the ones obtained using a standard irreducible finite element formulation, where displacements are the only unknowns of the finite element problem. Figure 8a compares the obtained capacity curves and Figure $8 \mathrm{~b}$ the damage distribution at a specific step of the analysis with the use of mixed (top row) and standard (bottom row) finite element formulations.

The two capacity curves present differences in stiffness, load capacity and post-peak response. In particular, the standard finite element formulation predicts a higher stiffness of around $15 \%$ and $8 \%$, and a higher load capacity of around $10 \%$ and $6 \%$ compared to the mixed formulation for the Pulling and the Pushing case, respectively. Additionally, the use of standard finite elements results in a higher residual strength at the post-peak region comparable to that obtained with the mixed formulation. Regarding the load predictions obtained from the most vulnerable Pulling case, the standard formulation predicts 
a higher capacity of $4.45 \%$ compared to the experimental one, while the mixed formulation gives a more conservative prediction of $5.21 \%$ lower than the maximum acceleration that the structure experiences during TEST05.

(a)

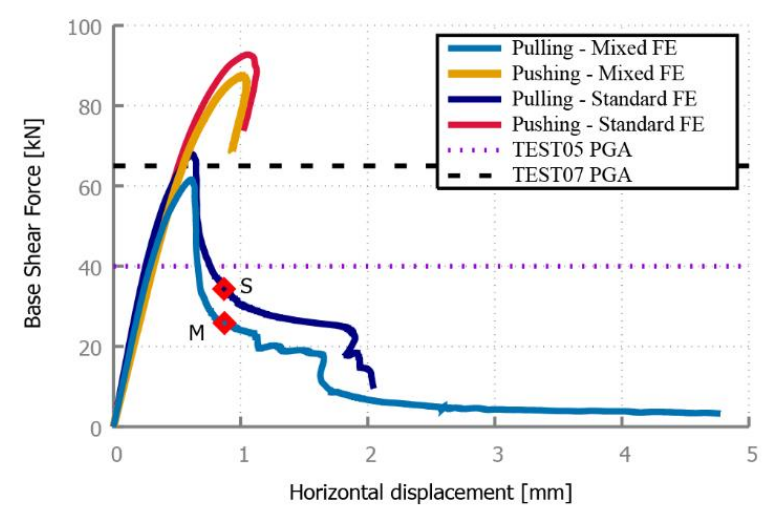

(b)

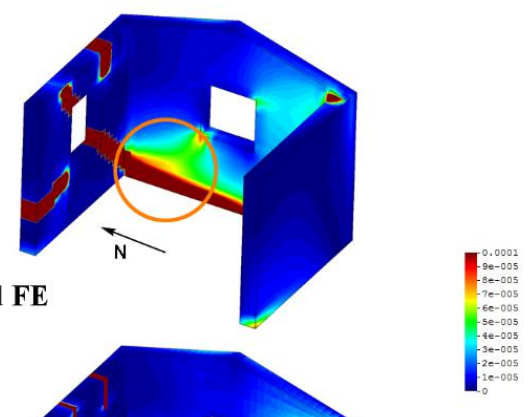

Standard FE

Figure 8 Comparison of results obtained with the mixed and standard formulation for the brick structure, in terms of (a) base shear force against horizontal displacement at the top of the gable, and (b) maximum principal strains contour at the numerical step depicted by the points on the graph for the mixed (top) and the standard (bottom) formulations for the Pulling case.

A closer look at the strain fields and crack propagation, shown in Figure 8b, highlights better the difference between the two finite element formulations. In the case of the standard FE formulation, the crack propagating from the low east corner of the window in the return wall cannot join the crack that has developed at the base of the façade. In particular, the crack direction at the northeast corner of the mock-up follows the mesh direction and spurious horizontal cracking appears at the third layer of elements from the base. This erroneous prediction of the crack direction hampers the evolution of the collapse mechanism and increases unrealistically the capacity and post-peak residual strength of the analysed structure. Mesh directionality biases the crack propagation also in the spandrel of the north wall, where the diagonal shear cracking is not predicted by the standard finite element formulation. On the contrary, the results with the mixed formulation seem to be practically mesh-independent, avoiding the aforementioned incorrect predictions of the structural response and damage pattern. 


\subsection{Stone Structure}

\subsubsection{Pushover analysis of the stone structure}

Figure 9 presents the structural response of the stone structure in terms of base shear force against horizontal displacement at the top of the cable. Similar to the brick mock-up, the structure appears to be more vulnerable in the $+\mathrm{X}$ direction (Pulling case).

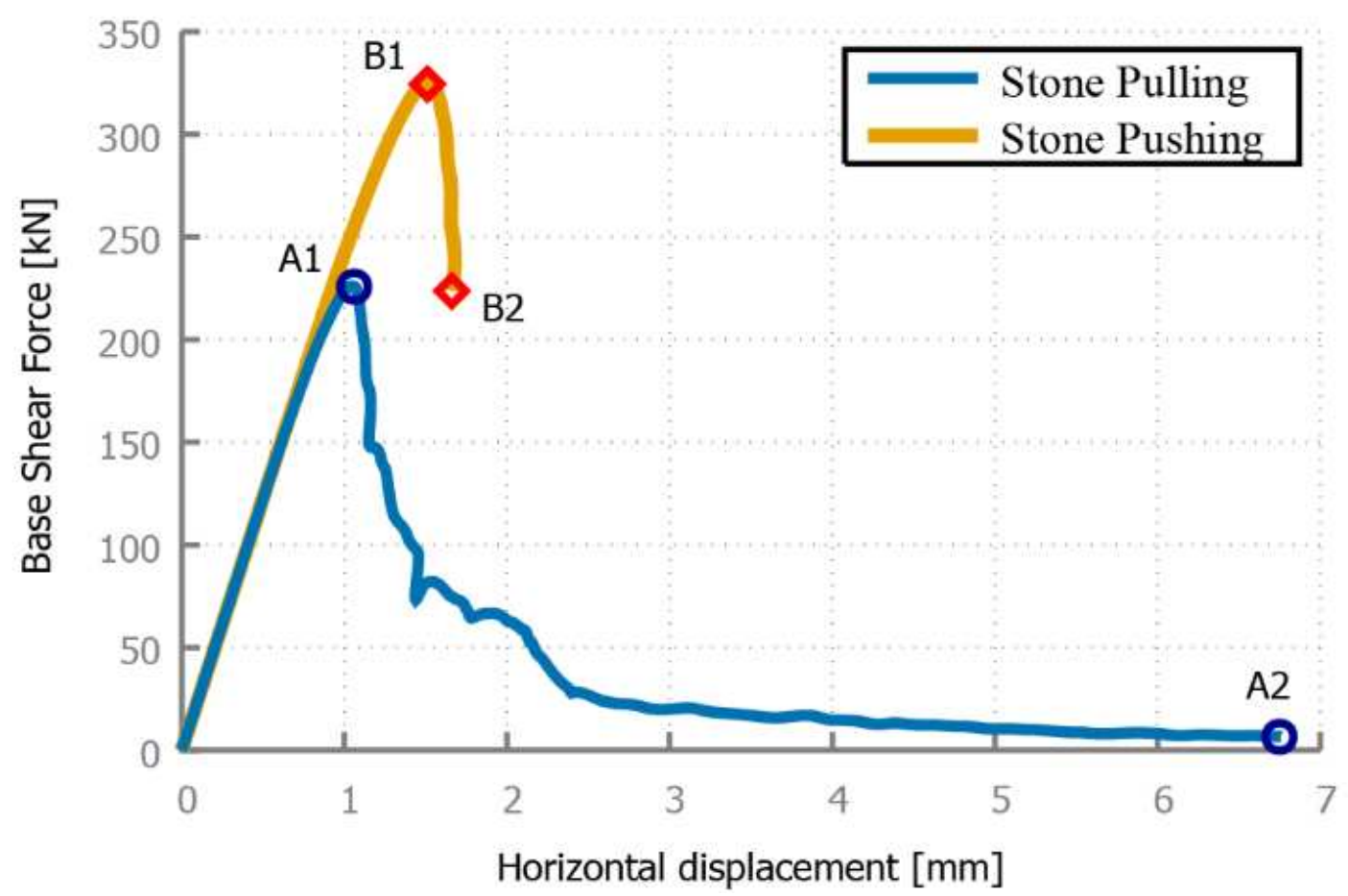

Figure 9 Base shear force against horizontal displacement at the top of the gable of the stone structure for both the Pulling $(+\mathrm{X})$ and Pushing $(-\mathrm{X})$ cases.

Starting with the Pulling case $(+X)$, the structure responds almost elastically until a base shear force of around $150 \mathrm{kN}$ is reached. At that point, damage initiates and stiffness starts to decrease up to a peak load of around $230 \mathrm{kN}$ is obtained. Figure 10a illustrates the open cracks (for elements with $\varepsilon_{\max } \geq 1.0710^{-4}$ ) at the peak load, through the contour of the maximum principal strain. Cracking exists at the base of the façade due to its vertical bending, while the tympanum presents a diffused high strain field. The out-of-plane loading of the façade results also in cracks at the connections with the return walls, especially at the top corners. Both return walls present some cracking at the west side of their base, due to their in-plane loading, while the north return wall is more vulnerable, with high concentration of strains around the window opening. More specifically, there is a crack starting at the low east corner of the window propagating diagonally towards the northeast 
corner. Moreover, a diagonal crack initiates at the northwest corner of the window. Finally, the spandrel presents significant strain concentration at its top east area.
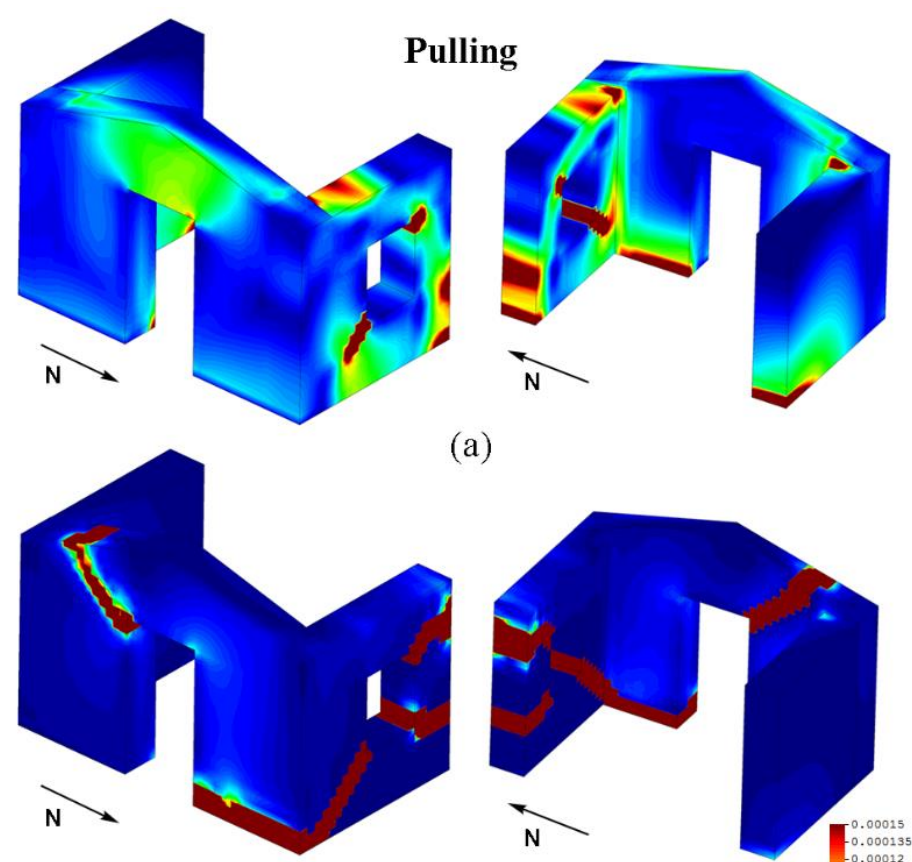

(a)
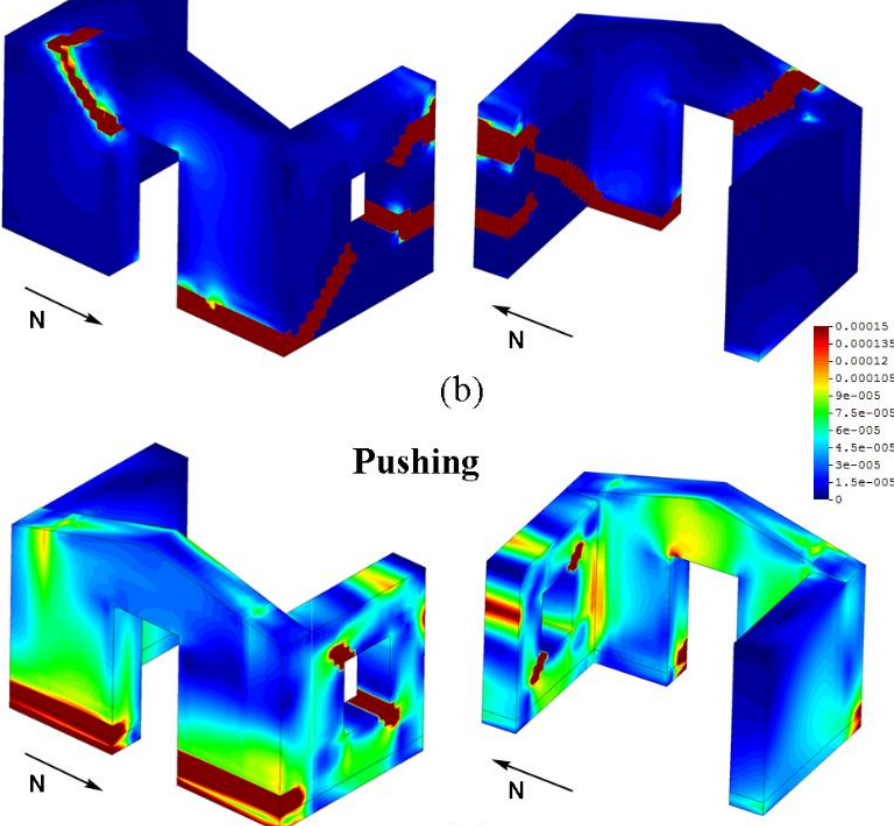

(b)

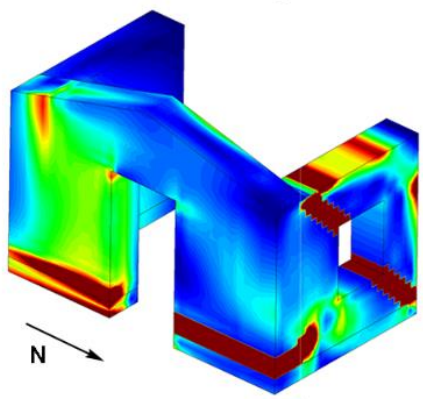

(c)

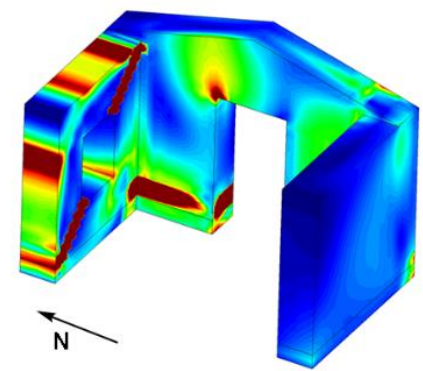

(d)

Figure 10 Contour of the maximum principal strains for the stone structure at different instances corresponding to the points of Figure 9: (a) A1 Pulling $(+X)$, (b) A2 Pulling $(+X)$, (c) B1 Pushing (-X) and (d) B2 Pushing (-X). 
Following the peak load, damage occurs at several locations of the structure. In particular, a vertical crack initiates at the north corner of the door and the connection of the façade with the blind return wall presents significant strain concentration. Another critical area is the top east part of the spandrel. Finally, the west pier of the north return wall develops significant strains at both the base and the top leading to a brittle failure. Due to the brittle failure of the west pier caused by the propagation of two cracks, the structure notably loses its load capacity and significant stress redistribution occurs. The area of the spandrel at the north wall unloads and the whole structure presents an important torsional response. Moreover, the diagonal crack at the east pier of the north return wall advances significantly, meeting the crack at the base of the north part of the façade. The above crack propagation provokes a local mechanism at the west pier, while a big portion of the northeast corner (including the spandrel, the east pier of the return wall and the north part of the facade) connects with the south part of the structure only through the gable of the façade. The increase of the displacements, amplifies the torsional response and a crack appears at the south top corner of the door and extends until the south top corner of the structure. Consequently, the northeast corner of the structure loses the connection with the south return wall. Figure $10 \mathrm{~b}$ shows the open cracks at the end of the analysis (point A2 in Figure 9).

In the Pushing case (-X), the response is almost elastic until a base shear force of around $250 \mathrm{kN}$ is attained, while the maximum capacity is of around $325 \mathrm{kN}$. During this part of the analysis, cracking develops simultaneously in two locations of the structure, in particular at the base of the façade due to its vertical bending, and at the north wall (Figure 10c). The post-peak response of the structure is determined by the propagation of two diagonal cracks at the north wall, causing a loss of load capacity and a brittle failure of the north-west corner, as shown in Figure 10d. At that point, the local collapse of the west part of the north return wall occurs and the local equilibrium is lost leading to the end of the analysis. Similar to the brick mock-up for the Pushing case, the analysis ends due to the loss of the stability of the west pier in the north wall and no further softening response is captured. 


\subsubsection{Comparison with Experimental Results}

As with the brick structure, the performance of the proposed simulation is investigated by comparing the obtained results with the experimental ones in terms of collapse mechanisms and load capacity. Before this, a brief summary of the experimental response and failure is presented, in order to facilitate the comparison with the numerical results.

According to Candeias et al. [55], an initial damage state was observed in the structure before the initiation of the experiment. This was a horizontal crack along the mortar joints above the first course of stones at the south return wall up to the door of the façade and some additional minor cracks at the northern side of the façade, represented with the light blue line in Figure 2b. Besides that, the structure started developing cracks during TEST03 and TEST04, while TEST05 marked its ultimate state. Already at TEST04, the damage extended at the north return wall, with cracks starting from the corners of the window and developing diagonally towards the corners of the wall. Additionally, significant damage was observed at the façade, dividing it into four parts: north pier, spandrel and two parts in the south pier. The formation of the collapse mechanism during TEST05 is described in the following. First, the top west corner of the north wall detached due to the impulses of the lintel above the window. The corresponding pier presented a rocking in-plane response facilitated by a diagonal crack at its base and the failure of the top corner. The northeast corner rocked in-plane due to the propagation of a diagonal crack from the base of the window towards the northeast lower corner. Subsequently, it split into two parts by diagonal cracks. Finally, the façade presented an out-of-plane rocking behaviour with a diagonal crack at its south pier and an approximately horizontal crack near the base at its north pier. The middle part of the gable was also separated from the piers due to vertical cracking occurring at both sides of the lintel. The collapse of the structure is determined by its torsional response, due to the weak north side wall, the high unit-to-structure size ratio, and the significant impact of the big lintels, which either stabilized or 'hammered' parts of the structure.

Once more, the outwards $(+\mathrm{X})$ direction appeared to be more vulnerable during the experiment [55] and this is correctly predicted by the numerical simulations as shown in Figure 9. Figure 11 presents a comparison of the experimental mechanism [75] (shown in Figure 11a) and the results obtained for the Pulling (Figure 11b) and Pushing (Figure 11c) cases with the proposed approach. Considering the results of both the Pulling and 
Pushing cases, the numerical model reproduces correctly the main aspects of the experimental collapse mechanism, while some differences exist due to micro-scale phenomena. In the experiment, the effect of the lintel at the north return wall changed the initial mechanism at the northeast pier, by restraining the evolution of the crack at the lower corner of the window and inducing a diagonal crack that divided it in two parts. Moreover, the lintel of the door played also an important role, since it provoked two vertical cracks at its sides. Finally, the high unit size caused a distributed damage pattern at the façade, while the numerical model could only provide localized damage patterns.

(a)
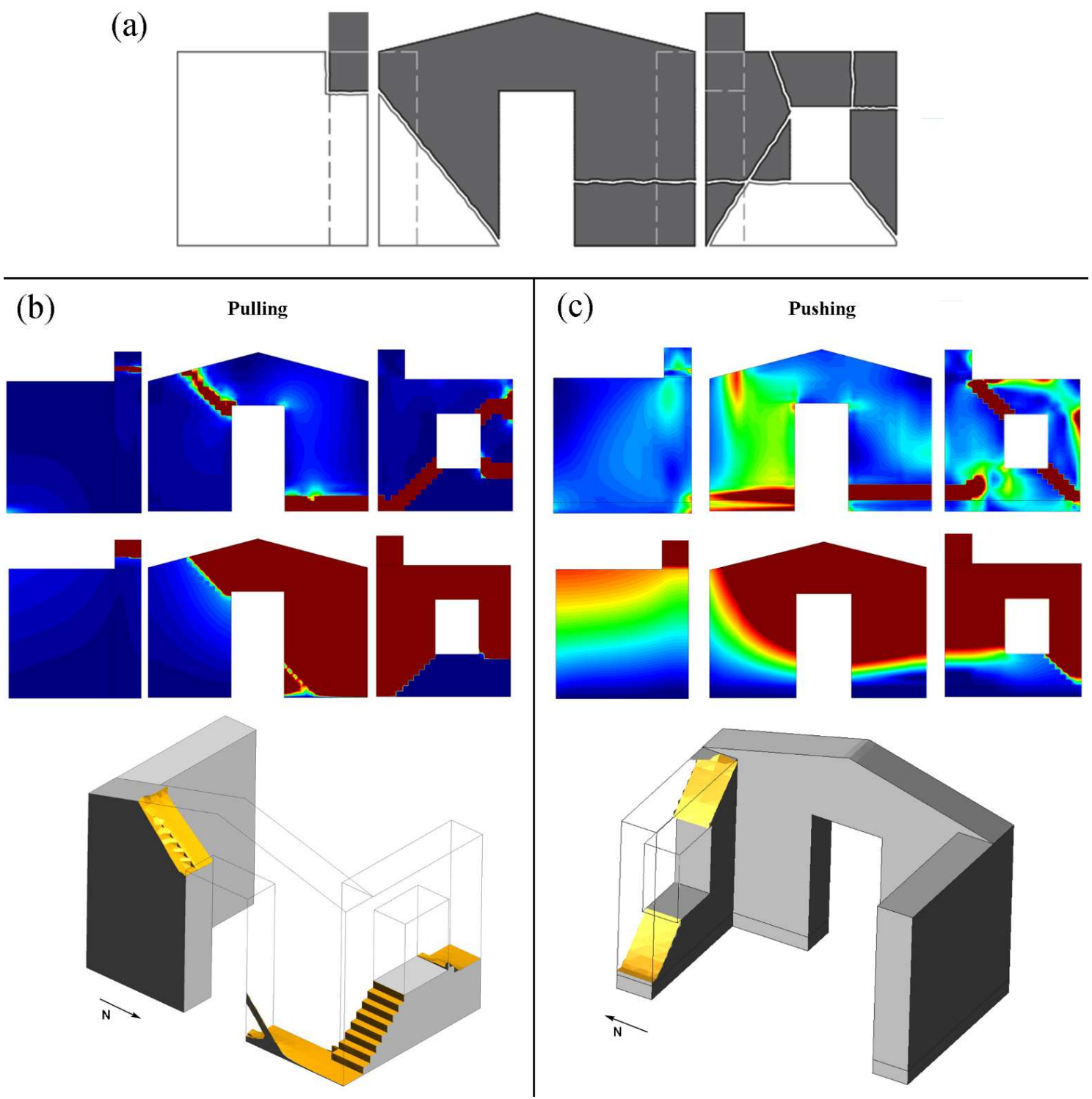

Figure 11 Comparison of the collapse mechanism formed for the stone structure with the numerical predicted one. (a) The experimental collapse mechanism (Figure adapted from Mendes et al. [76]), (b) maximum principal strains (top), displacements contour (middle) and crack surface (bottom) at point A2 of Figure 9, and (c) maximum principal strains (top), displacements contour (middle) and crack surface (bottom) at point B2 of Figure 9. 


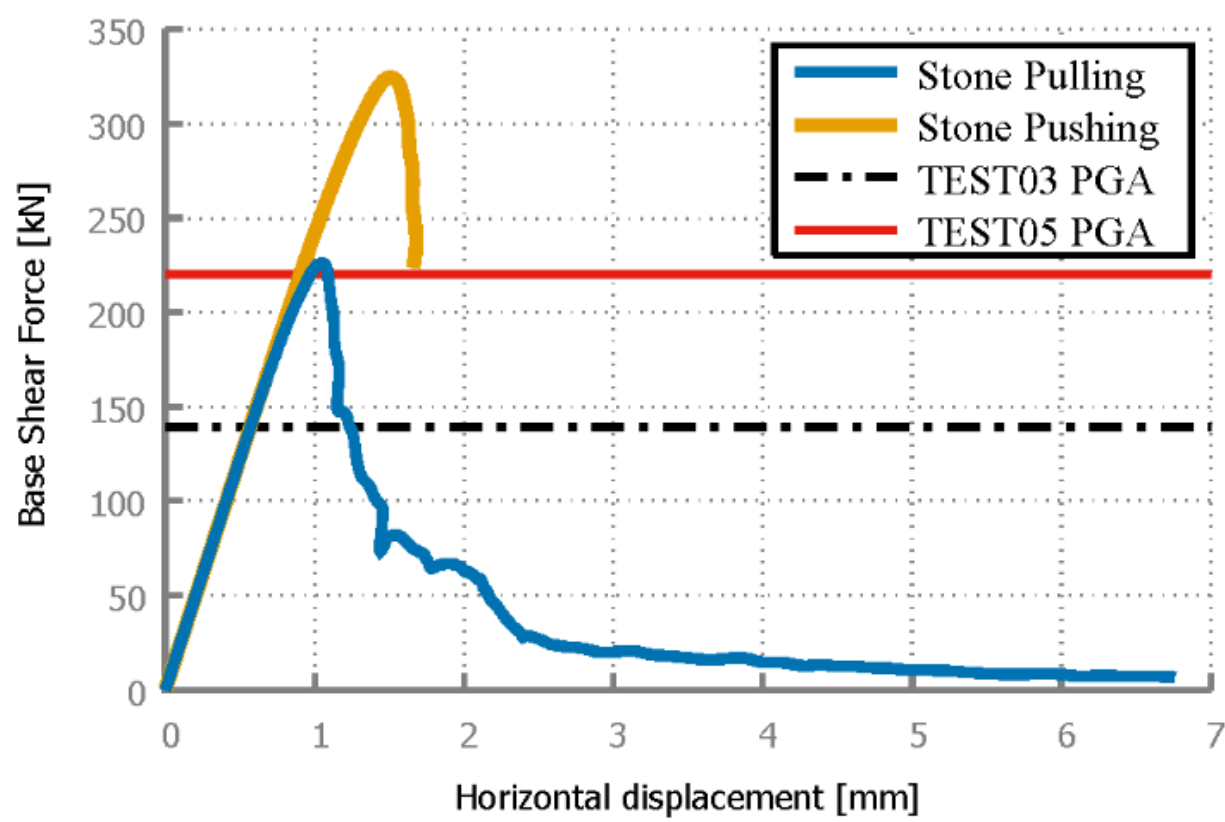

Figure 12 Comparison of base shear force against horizontal displacement at the top of the gable of the stone structure with the corresponding experimental PGAs of TEST03 and TEST05.

Candeias et al. [55] describe that the collapse mechanism of the stone structure started to form during TEST03, while TEST05 marked its completion. Similar to the brick mockup structure, the base shear values corresponding to the PGAs of these two TESTs are reported together with the capacity curves of the numerical model in Figure 12. More specifically, the black dashed line corresponding to TEST03 highlights the damage initiation (stiffness degradation) of the structure, while the red continuous one depicting TEST07 indicates the load peak at which the mechanism is formed. As for the brick structure, the experimental and numerical results correspond for the most vulnerable Pulling $(+\mathrm{X})$ direction.

\subsubsection{Comparison with Standard Finite Elements}

Figure 13 shows the results of the mixed finite element formulation along with those obtained with the standard one. As for the brick mock-up, the standard formulation results in increased stiffness of around 8\%, higher load capacity of around $13 \%$ and higher residual strength for the Pulling case $(+X)$. In the Pushing case $(-X)$, the increase of the stiffness given by the standard formulation is again $8 \%$, while minor differences are observed in the base shear force against horizontal displacement graphs between the two formulations. Interestingly, and despite these similarities in the Pushing case, the two FE formulations predict a different final collapse mechanism, as shown in Figure 13b. In 
particular, in the standard irreducible formulation the mesh orientation biases the propagation of a crack along the whole base of the north return wall. In this case, the analysis stops due to a sliding failure at the base of the structure, while in the mixed FE formulation due to a local mechanism at the north return wall, as discussed in Section 4.2.1. The orientation of the finite element mesh erroneously affects the predictions regarding the collapse mechanism of the standard FE formulation. This case demonstrates again the directional mesh-bias dependency of standard finite elements and its effect in the prediction of inaccurate collapse mechanisms.

Similar to the results of the brick structure, the mixed formulation predicts also for this case a more conservative load capacity for the most vulnerable Pulling Case. This has a difference of $2.69 \%$ comparing to the experimental one, while the standard formulation predicts a higher load capacity of $15.90 \%$ compared to the maximum acceleration applied to the structure during TEST05.

(a)

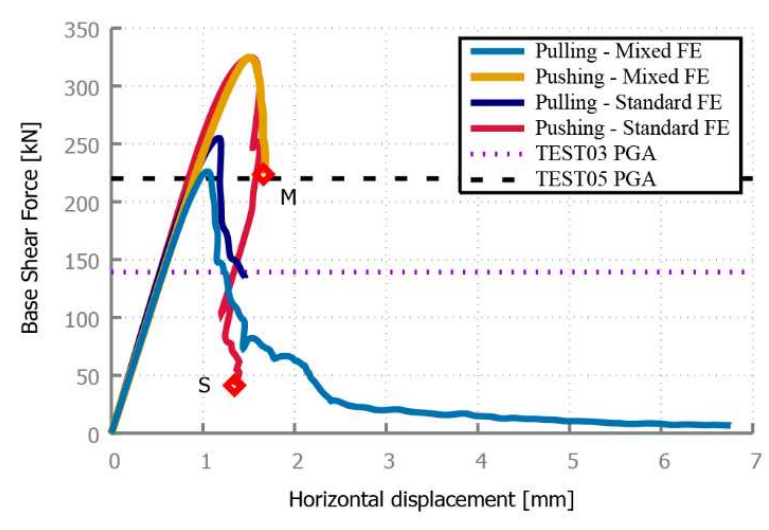

(b)

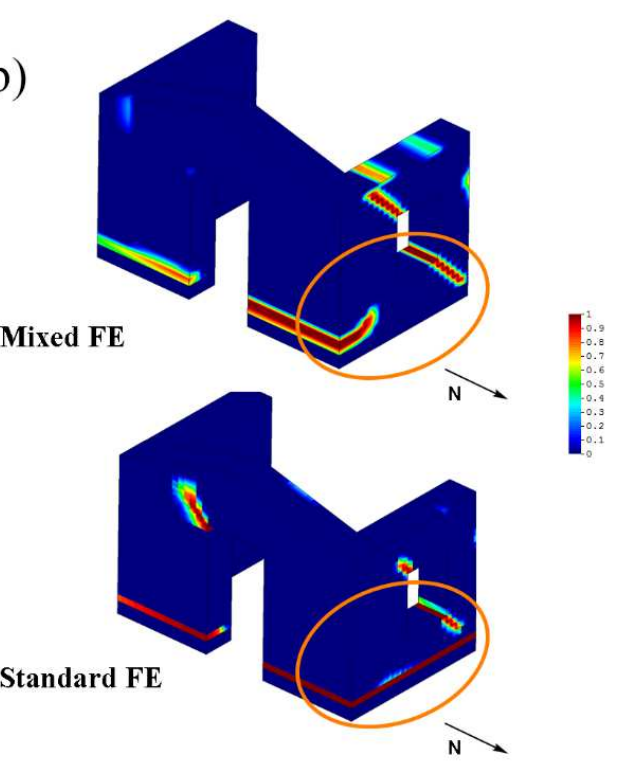

Figure 13 Comparison of results obtained with the mixed and standard formulation for the stone structure, in terms of (a) base shear force against horizontal displacement at the top of the gable, and (b) maximum principal strains contour at the numerical step depicted by the points on the graph for the mixed (top) and the standard (bottom) formulations for the Pushing case.

\subsection{Computational Cost}

The enhanced strain accuracy of the mixed formulation is the result of considering six strain components at each node as unknowns, additionally to the three displacement components that are considered in standard finite elements. The higher number of nodal variables increases the computational cost of each numerical iteration. On the other hand, 
the enhanced accuracy of the mixed formulation in high non-linear problems usually leads to less iterations for reaching equilibrium convergence compared with the standard formulation.

Table 2 presents the computational overhead using the mixed formulation instead of the standard one in terms of CPU time and RAM memory requirements. Regarding the sizes of the models, the brick and the stone structure are composed by 7428 and 6931 nodes, respectively. The results show an average increase of $300 \%$ for the CPU time and $42 \%$ of RAM memory.

The computational efficiency is a key for the simulation of large-scale masonry structures. A way to reduce the computational cost of the mixed FE formulation is by taking advantage of the compatibility between mixed and standard finite elements as presented in Benedetti et al. [52]. In particular, mixed finite elements can be used only at zones where high stress gradients are expected, while the rest of the structure can be discretized using standard finite elements. Apart from this, the adaptive substitution of standard finite elements with mixed ones in areas with increasing strain gradients during the numerical analysis is feasible.

Table 2 Computational overhead in terms CPU and RAM requirements when using mixed finite elements over standard ones

Overhead using the mixed FE formulation (\%)

\begin{tabular}{cccc} 
& Case & CPU & RAM \\
\hline \multirow{2}{*}{ Brick Structure } & Pulling $(+\mathrm{X})$ & 182.56 & 41.11 \\
& Pushing $(-\mathrm{X})$ & 231.13 & 41.76 \\
& & & 42.09 \\
Stone Structure & Pulling $(+\mathrm{X})$ & 327.36 & 42.62 \\
& & & \\
\hline
\end{tabular}




\section{Comparative study of mesh-dependence using standard and mixed FE}

This section investigates the mesh-dependency of the standard and mixed FE formulations under mixed Mode I and II in-plane (Section 5.1) and out-of-plane (Section 5.2) loading. This study complements the one presented in reference [49] where the relative performance of standard and mixed FE was analyzed for Mode I cracking.

\section{$5.1 \quad$ In-plane loading}

The simulation of a shear wall with dimensions of $1 \mathrm{~m} \times 1 \mathrm{~m} \times 0.1 \mathrm{~m}$ and a central opening of $0.2 \mathrm{~m} \times 0.2 \mathrm{~m}$ under in-plane loading is considered. The base of the wall is completely constrained while the top is subjected to a simultaneous compressive vertical displacement and a horizontal shearing displacement. The applied incremental displacement ratio is $\Delta u_{y}: \Delta u_{x}=-1: 0.74$ until collapse. The expected developing crack angle is different from $45^{\circ}$ due to the combination of compression and shear. The mechanical parameters considered are Young's modulus $E=7.5 \mathrm{GPa}$, Poisson's ratio $v=0.0$, uniaxial tensile strength $f_{t}=0.35 \mathrm{MPa}$ and fracture energy $G_{f}=5 \mathrm{~N} / \mathrm{m}$. The wall is discretized with constant strain triangular finite elements of varying sizes and orientations. Analyses are performed with the standard and the mixed strain/displacement formulation.

Figure 14 illustrates the analysis results obtained with fully structured meshes and two different element sizes of $33 \mathrm{~mm}$ (top row in Figure 14) and $20 \mathrm{~mm}$ (middle row in Figure 14). Crack trajectories obtained with standard FE present a spurious mesh-dependency, as they are initially aligned with the vertical direction of the mesh close to the window corners and with the diagonal one far of them. The simulations with the mixed FE give in both cases cracks with the same direction, independently of the used mesh-pattern and element size. The last row of Figure 14 illustrates the deformation of the wall and the contour of the maximum principal strains obtained using the mixed FE formulation.

Figure 15 presents the analysis results using two unstructured meshes with element size of $30 \mathrm{~mm}$ (top row in Figure 15) and $20 \mathrm{~mm}$ (bottom row in Figure 15). As in the case of the structured meshes, the standard FE formulation predicts cracks that follow a path designated by the mesh orientation. On the contrary, the mixed formulation is able to predict in all the cases the same crack trajectory independently of the used mesh. Note that in the first mesh considered in Figure 15 (top row), with an element size of $30 \mathrm{~mm}$, the computed upper-right crack path is similar in the standard and mixed FE formulations because the 
mesh is well oriented with respect to the developing crack. Contrariwise, the lower-left crack path is not identical because the unstructured mesh orientation is not favorable in that region.

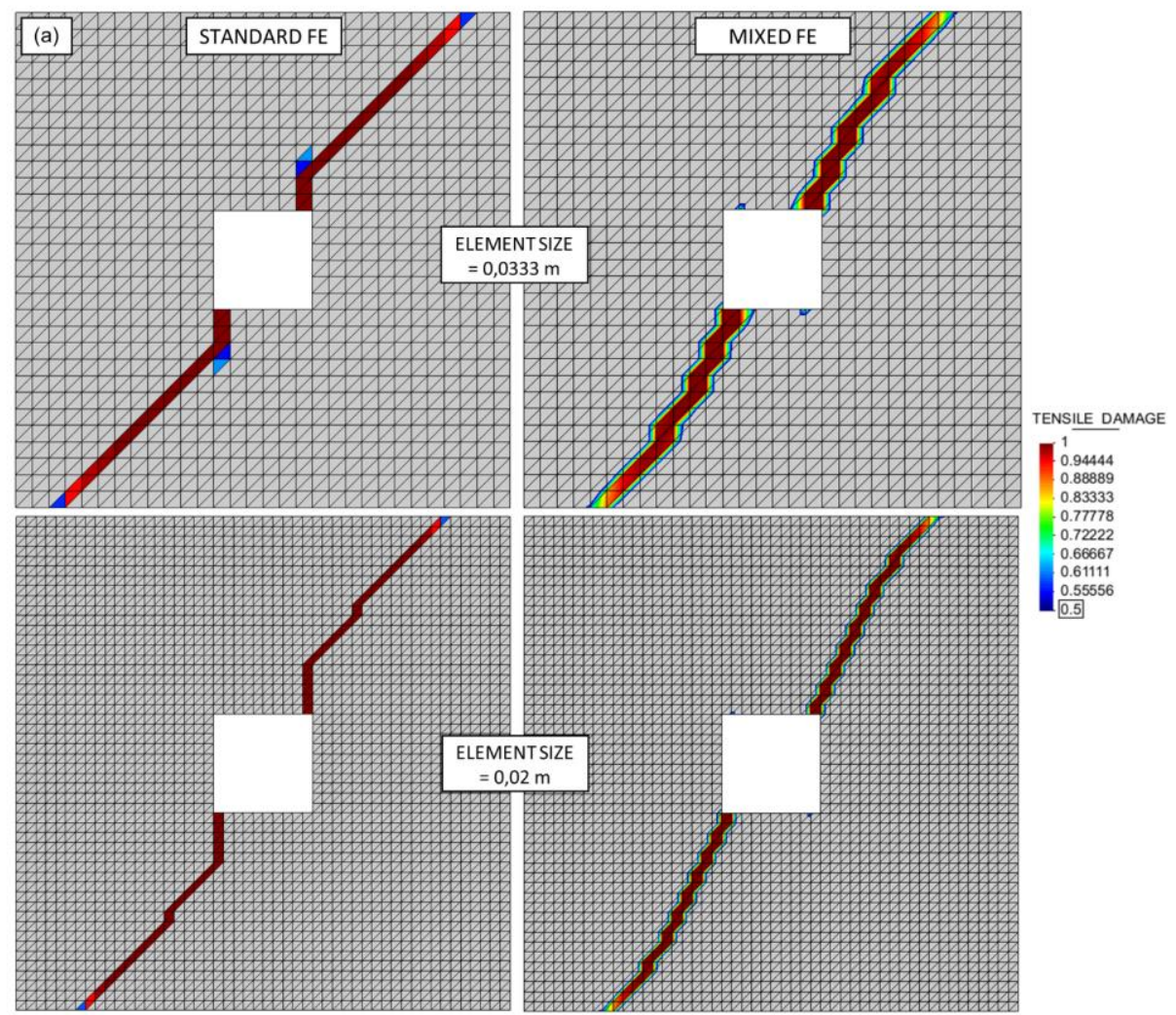

(b)

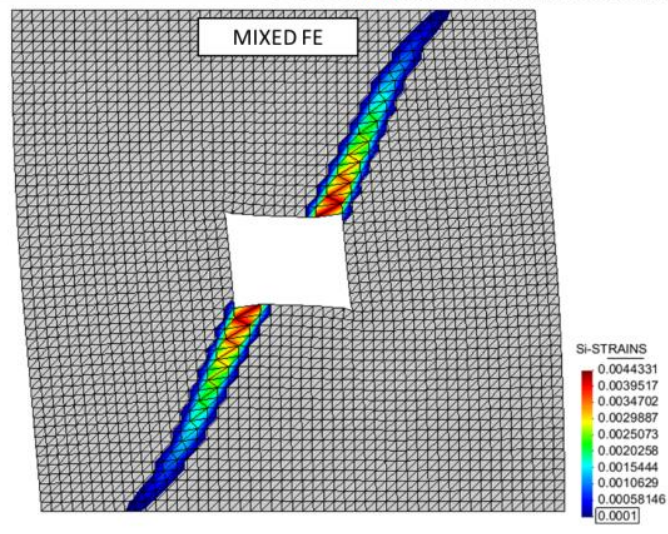

Figure 14 Mesh-dependence study for in-plane loading using structured meshes with varying element size: (a) damage contours using standard FE (left) and mixed FE (right) and (b) maximum principal strains using mixed FE (deformed shape $\mathrm{x} 300$ ). 


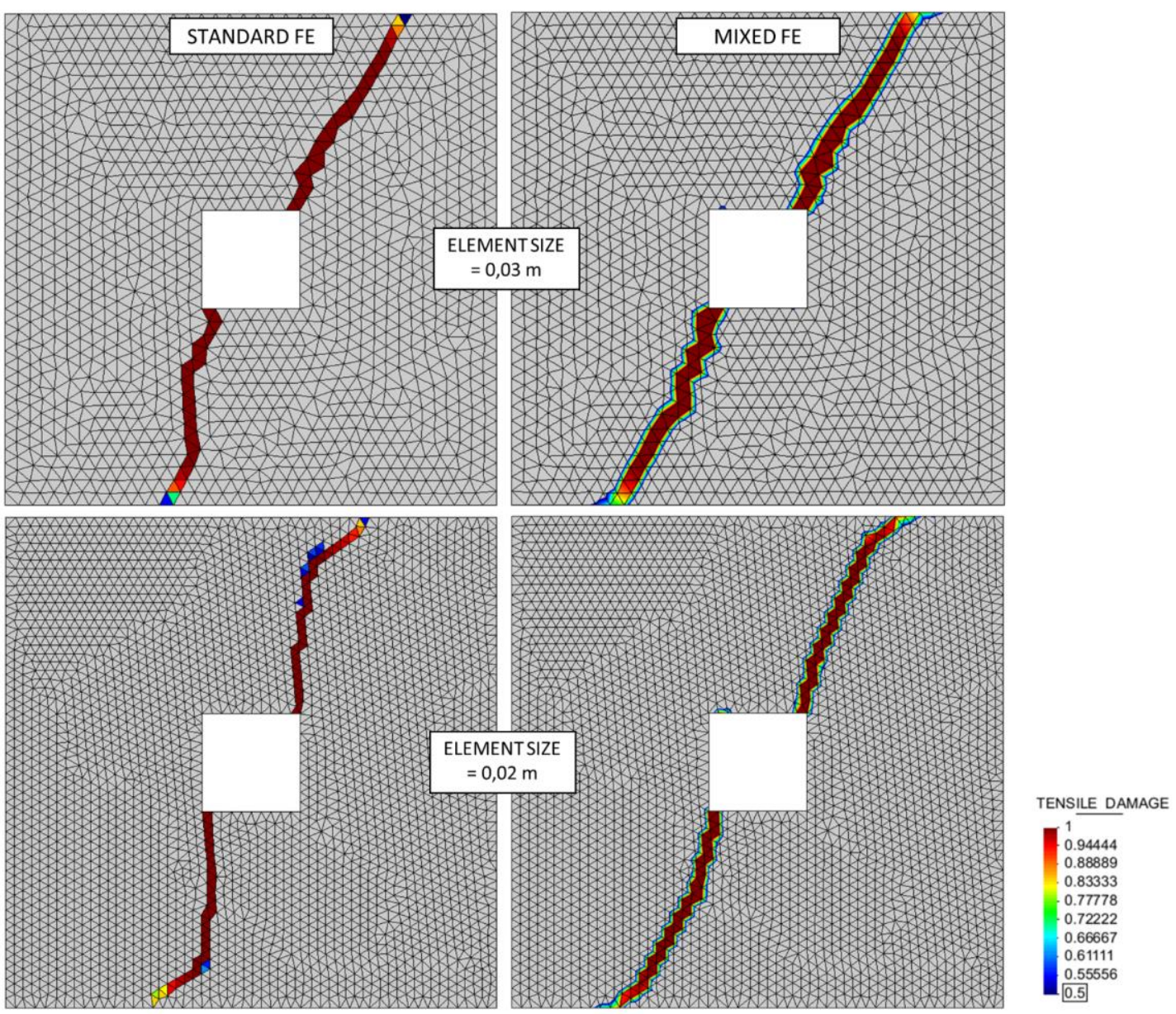

Figure 15 Mesh-dependence study for in-plane loading and unstructured meshes with varying element size: damage contours using standard FE (left) and mixed FE (right).

\subsection{Out-of-plane loading}

A wall with the same geometry and properties as the one in the previous section is subjected now to out-of-plane loading. A displacement in the out-of-plane direction of the wall of $5 \cdot 10^{-3} \mathrm{~m}$ is prescribed to at the top of the wall, while the base is fixed. For this case, no compressive vertical displacement is applied.

Simulations are performed using standard and mixed finite elements. Two different meshes of hexahedra of size $50 \mathrm{~mm} \times 50 \mathrm{~mm}$ are considered, with 2 (top row of Figure 16) and 4 elements (middle row of Figure 16) across the thickness, respectively.

The computed results with standard FEs (left column of Figure 16) demonstrate that for both meshes cracking appears across the whole thickness at the top and bottom of the wall. For the same out-of-plane action, the mixed formulation gives a solution where damage does not cross yet the whole thickness of the wall. The enhanced strain accuracy 
given by the mixed FE formulation succeeds in simulating the expected tension-compression state at the top and bottom parts of the wall induced by the out-of-plane bending. This situation, commonly encountered in masonry structures, cannot be accurately reproduced using standard finite elements. This is because with standard FE gives stiffer results than those obtained with the mixed FE and stiffer than the "true" solution (see [48]). Therefore, the computed effective stresses are greater with the standard FE and damage originates earlier. As shown in Figure 16, the over-stiffness of standard FE is not alleviated when refining the mesh only across the thickness. As a result, a failure condition that refers to sliding and not bending is predicted, which does not correspond to the analysed problem. The last row of Figure 16 illustrates the deformation of the wall and the contour of the maximum principal strains for the out-of-plane collapse mechanism using mixed FEs. 


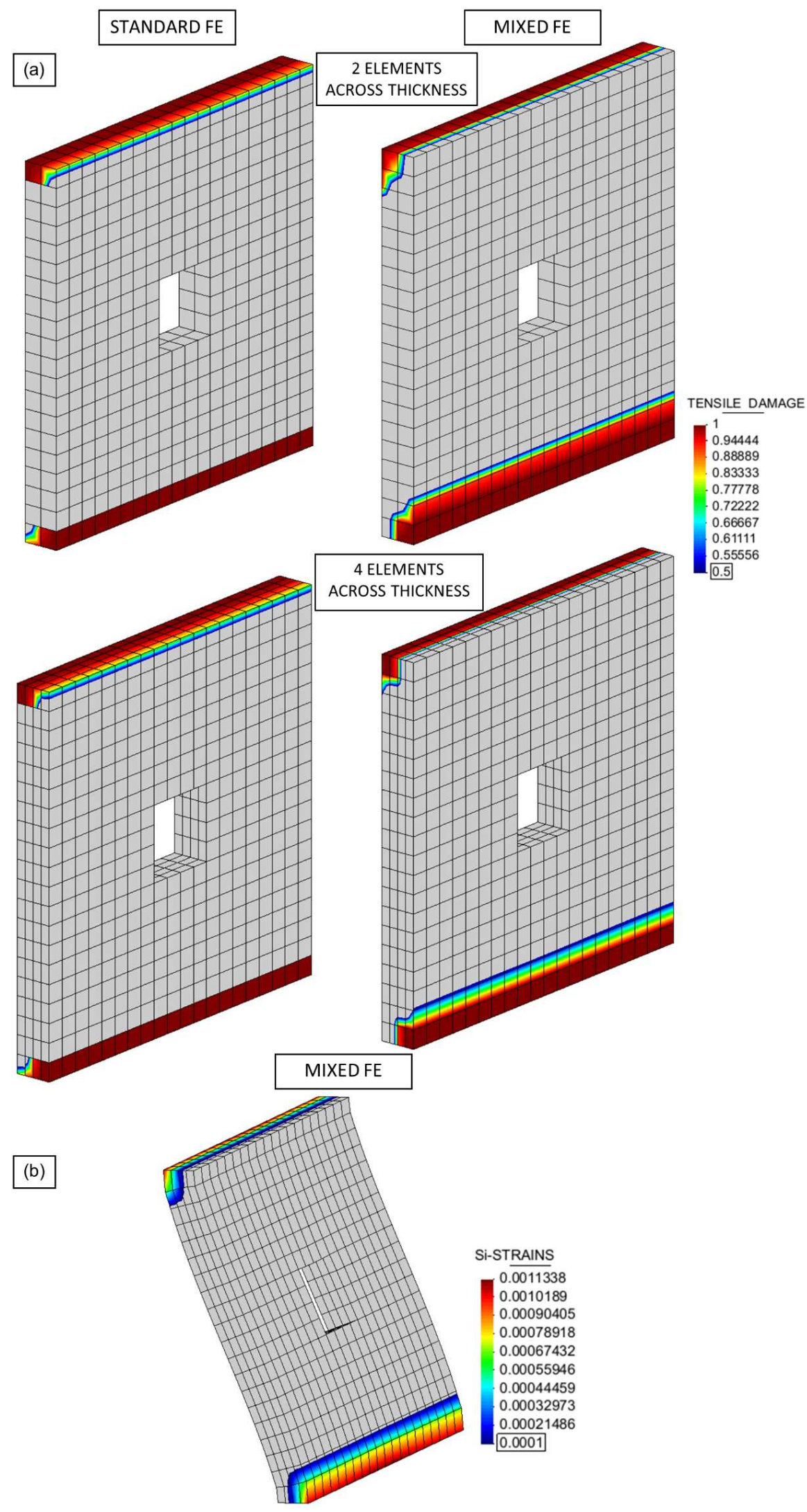

Figure 16 Mesh-dependence study for out-of-plane loading with varying element size per wall thickness: (a) damage contours using standard FE (left) and mixed FE (right) and (b) maximum principal strain using mixed FE (deformed shape $\mathrm{x} 300$ ). 


\section{Conclusions}

This work presents the application and assesses the performance of the mixed strain/displacement FE formulation on the out-of-plane response of two unreinforced masonry structures. The use of the mixed FE formulation aims to enhance the strain accuracy of the finite element solution and aid the mesh-independent strain localization in crack propagation problems.

A campaign of a brick and a stone structure subjected to shaking table tests is chosen as benchmark case, being one of the most challenging topics in the simulation of unreinforced masonry structures. The effect of the seismic action is considered in the numerical analysis through equivalent non-linear static analyses. The simulations are compared with the experimental outcomes in terms of collapse mechanism formation and load carrying capacity.

The results of the performed analyses are in good agreement with the experiments. The numerical simulations could capture the in-plane response and early failure of the weak return walls, the torsional effects associated with this failure and the out-of-plane collapse of the façades. Moreover, the damage pattern and collapse mechanism are also correctly predicted and a good agreement has been found for the load carrying capacity. Differences between the experimental and numerical outcomes are attributed either to microscale phenomena, or to the dynamic and accumulating nature of the experiment, which are neglected in the numerical simulations.

The enhanced accuracy of the mixed formulation is highlighted by comparing the results obtained with the standard irreducible FE formulation. The standard formulation presents higher stiffness and peak load strength, while significant residual strength is observed at the softening region, since some developing cracks are biased by the mesh orientation. Specifically for one of the investigated cases, the mesh-biased solution of the standard formulation results in the prediction of a different collapse mechanism than the experimental one. On the other hand, the results of the mixed formulation do not appear to suffer from any mesh dependency, justifying their benefits in crack propagation analysis of unreinforced masonry structures, albeit their higher computational cost.

The above superiority of the mixed formulation against the standard one in strain localization problems is corroborated through a mesh-dependence study using both the mixed and standard FE simulation on two benchmark in-plane and out-of-plane problems. The standard formulation predicts crack trajectories that are biased by the orientation of FE 
mesh for all the situations analyzed. On the other hand, mixed FE provide much more reliable results, which seem to be practically free of mesh-bias and avoid incorrect predictions of the structural response, the damage pattern and the collapse mechanism of the structure.

\section{Acknowledgements}

This research has received the financial support from the MINECO (Ministerio de Economia y Competitividad of the Spanish Government) through the MULTIMAS project (Multiscale techniques for the experimental and numerical analysis of the reliability of masonry structures, ref. num. BIA2015-63882-P).

The support provided by the Spanish Ministry of Education for the Ph.D. research of Gabriel Barbat via an FPU grant is acknowledged.

This research was supported by the European Union within the framework of the Erasmus Mundus Advanced Master in Structural Analysis of Monuments and Historical Constructions (SAHC).

\section{References}

[1] M. Javed, A. Naeem, A. Penna, G. Magenes, Behavior of masonry structures during the Kashmir 2005 earthquake, in: 1st Eur. Conf. Earthq. Eng. Seismol., Geneva, Switzerland, 2005.

[2] N. Augenti, F. Parisi, Learning from Construction Failures due to the 2009 L'Aquila, Italy, Earthquake, J. Perform. Constr. Facil. 24 (2010) 536-555. doi:10.1061/(ASCE)CF.1943-5509.0000122.

[3] D. Dizhur, J. Centeno, C. Ventura, J. Leite, P. Lourenco, J. Ingham, L. Moon, M. Griffith, A. Schultz, I. Senaldi, G. Magenes, J. Dickie, S. Lissel, Performance of Masonry Buildings and Churches in the 22 February 2011 Christchurch Earthquake, Bull. New Zeal. Soc. Earthq. Eng. 44 (2011) 279-296.

[4] D.F. D'Ayala, S. Paganoni, Assessment and analysis of damage in L'Aquila historic city centre after 6th April 2009, Bull. Earthq. Eng. (2011). doi:10.1007/s10518-010-9224-4.

[5] A. Penna, P. Morandi, M. Rota, C.F. Manzini, F. da Porto, G. Magenes, Performance of masonry buildings during the Emilia 2012 earthquake, Bull. Earthq. Eng. (2014). doi:10.1007/s10518-013-9496-6.

[6] H. Varum, R. Dumaru, A. Furtado, A.R. Barbosa, D. Gautam, H. Rodrigues, 
Seismic Performance of Buildings in Nepal After the Gorkha Earthquake, in: Impacts Insights Gorkha Earthq. Nepal, 2018. doi:10.1016/B978-0-12-8128084.00003-1.

[7] X. Romão, A.A. Costa, E. Paupério, H. Rodrigues, R. Vicente, H. Varum, A. Costa, Field observations and interpretation of the structural performance of constructions after the 11 May 2011 Lorca earthquake, Eng. Fail. Anal. 34 (2013) 670-692. doi:10.1016/j.engfailanal.2013.01.040.

[8] A. Menon, G. Magenes, Out-of-plane seismic response of unreinforced masonry : definition of seismic input, Rose School, IUSS Press, 2008.

[9] P.B. Lourenço, J.M. Leite, M.F. Paulo-Pereira, A. Campos-Costa, P.X. Candeias, N. Mendes, Shaking table testing for masonry infill walls: unreinforced versus reinforced solutions, Earthq. Eng. Struct. Dyn. 45 (2016) 2241-2260. doi:10.1002/eqe. 2756 .

[10] D.P. Abrams, O. AlShawa, P.B. Lourenço, L. Sorrentino, Out-of-Plane Seismic Response of Unreinforced Masonry Walls: Conceptual Discussion, Research Needs, and Modeling Issues, Int. J. Archit. Herit. 11 (2017) 22-30. doi:10.1080/15583058.2016.1238977.

[11] T.M. Ferreira, A.A. Costa, A. Costa, Analysis of the Out-Of-Plane Seismic Behavior of Unreinforced Masonry: A Literature Review, Int. J. Archit. Herit. 9 (2015) 949-972. doi:10.1080/15583058.2014.885996.

[12] L. Sorrentino, D. D’Ayala, G. de Felice, M.C. Griffith, S. Lagomarsino, G. Magenes, Review of Out-of-Plane Seismic Assessment Techniques Applied To Existing Masonry Buildings, Int. J. Archit. Herit. 11 (2017) 2-21. doi:10.1080/15583058.2016.1237586.

[13] G. de Felice, S. De Santis, P.B. Lourenço, N. Mendes, Methods and Challenges for the Seismic Assessment of Historic Masonry Structures, Int. J. Archit. Herit. 11 (2016) 1-18. doi:10.1080/15583058.2016.1238976.

[14] J. Heyman, The stone skeleton, Int. J. Solids Struct. 2 (1966) 249-279. doi:10.1016/0020-7683(66)90018-7.

[15] D.P. Abrams, R. Angel, J. Uzarski, Out-of-plane strength of unreinforced masonry infill panels, Earthq. Spectra. 12 (1996) 825-844. doi:10.1193/1.1585912.

[16] K. Doherty, An investigation of the weak links in the seismic load path of unreinforced masonary buildings, University of Adelaide, 2000. 
doi:10.1155/2015/183712.

[17] M.C. Griffith, G. Magenes, G. Melis, L. Picchi, Evaluation of out-of-plane stability of unreinforced masonry walls subjected to seismic excitation, J. Earthq. Eng. (2003). doi:10.1080/13632460309350476.

[18] D. D’Ayala, E. Speranza, Definition of Collapse Mechanisms and Seismic Vulnerability of Historic Masonry Buildings, Earthq. Spectra. (2003). doi:10.1193/1.1599896.

[19] P. Block, T. Ciblac, J. Ochsendorf, Real-time limit analysis of vaulted masonry buildings, Comput. $\quad$ Struct. $\quad 84 \quad$ (2006) 1841-1852. doi:10.1016/j.compstruc.2006.08.002.

[20] M.J. DeJong, Seismic Assessment Strategies for Masonry Structures, PhD thesis, Massachusets Institute of Technology, 2009.

[21] J. Vaculik, Unreinforced masonry walls subjected to out-of-plane seismic actions, University of Adelaide, 2012.

[22] H. Derakhshan, M.C. Griffith, J.M. Ingham, Airbag testing of multi-leaf unreinforced masonry walls subjected to one-way bending, Eng. Struct. 57 (2013) 512-522. doi:10.1016/j.engstruct.2013.10.006.

[23] P. Roca, M. Cervera, G. Gariup, L. Pelà, Structural Analysis of Masonry Historical Constructions. Classical and Advanced Approaches, Arch. Comput. Methods Eng. 17 (2010) 299-325. doi:10.1007/s11831-010-9046-1.

[24] D. Theodossopoulos, B. Sinha, A review of analytical methods in the current design processes and assessment of performance of masonry structures, Constr. Build. Mater. 41 (2013) 990-1001. doi:10.1016/j.conbuildmat.2012.07.095.

[25] D. Addessi, S. Marfia, E. Sacco, J. Toti, Modeling Approaches for Masonry Structures, Open Civ. Eng. J. (2014) 288-300.

[26] L. Gambarotta, S. Lagomarsino, Damage models for the seismic response of brick masonry shear walls. Part I: The mortar joint model and its applications, Earthq. Eng. Struct. Dyn. 26 (1997) 423-439. doi:10.1002/(SICI)10969845(199704)26:4<423::AID-EQE650>3.0.CO;2-\#.

[27] D. Addessi, E. Sacco, A multi-scale enriched model for the analysis of masonry panels, Int. J. Solids Struct. 49 (2012) 865-880. doi:10.1016/j.ijsolstr.2011.12.004.

[28] L. Macorini, B.A. Izzuddin, A non-linear interface element for 3D mesoscale analysis of brick-masonry structures, Int. J. Numer. Methods Eng. 85 (2011) 15841608. doi:10.1002/nme.3046. 
[29] M. Petracca, L. Pelà, R. Rossi, S. Oller, G. Camata, E. Spacone, Multiscale computational first order homogenization of thick shells for the analysis of out-ofplane loaded masonry walls, Comput. Methods Appl. Mech. Eng. 315 (2017) 273301. doi:10.1016/j.cma.2016.10.046.

[30] A.P. Alexandris, E. Protopapa, I. Psycharis, Collapse mechanisms of masonry buildings drived by the distinct element method, Proc. 13th World Conf. Earthq. Eng. (2004) No.548.

[31] J. V. Lemos, Discrete Element Modeling of Masonry Structures, Int. J. Archit. Herit. 1 (2007) 190-213. doi:10.1080/15583050601176868.

[32] J.V. Lemos, A. Campos Costa, Simulation of Shake Table Tests on Out-Of-Plane Masonry Buildings. Part (V): Discrete Element Approach, Int. J. Archit. Herit. 00 (2016) 1-8. doi:10.1080/15583058.2016.1237587.

[33] O. AlShawa, L. Sorrentino, D. Liberatore, Simulation Of Shake Table Tests on Out-of-Plane Masonry Buildings. Part (II): Combined Finite-Discrete Elements, Int. J. Archit. Herit. 11 (2016) 1-15. doi:10.1080/15583058.2016.1237588.

[34] G. Milani, P.B. Lourenço, A. Tralli, Homogenised limit analysis of masonry walls, Part I: Failure surfaces, Comput. Struct. 84 (2006) 166-180. doi:10.1016/j.compstruc.2005.09.005.

[35] G. Milani, G. Venturini, Safety Assessment of Four Masonry Churches by a Plate and Shell FE Non-Linear Approach, J. Perform. Constr. Facil. (2011) 230. doi:10.1061/(ASCE)CF.1943-5509.0000321.

[36] A. Chiozzi, G. Milani, N. Grillanda, A. Tralli, A fast and general upper-bound limit analysis approach for out-of-plane loaded masonry walls, Meccanica. (2018). doi:10.1007/s11012-017-0637-x.

[37] L.C. Silva, P.B. Lourenço, G. Milani, Nonlinear Discrete Homogenized Model for Out-of-Plane Loaded Masonry Walls, J. Struct. Eng. (2017). doi:10.1061/(ASCE)ST.1943-541X.0001831.

[38] A. Zucchini, P.B. Lourenço, A micro-mechanical homogenisation model for masonry: Application to shear walls, Int. J. Solids Struct. 46 (2009) 871-886. doi:10.1016/j.ijsolstr.2008.09.034.

[39] P.B. Lourenço, Computations on historic masonry structures, Prog. Struct. Eng. Mater. 4 (2002) 301-319. doi:10.1002/pse.120.

[40] S. Saloustros, L. Pelà, M. Cervera, P. Roca, An Enhanced Finite Element Macro- 
Model for the Realistic Simulation of Localized Cracks in Masonry Structures: A Large-Scale Application, Int. J. Archit. Herit. 12 (2018) 432-447. doi:10.1080/15583058.2017.1323245.

[41] F. Clementi, E. Quagliarini, F. Monni, E. Giordano, Lenci, S., Cultural Heritage and Earthquake: The Case Study of "Santa Maria della Carità" in Ascoli Piceno, Open Civ. Eng. J. 11 (2017) 1079-1105. doi:10.2174/1874149501711011079.

[42] M.P. Ciocci, S. Sharma, P.B. Lourenço, Engineering simulations of a supercomplex cultural heritage building: Ica Cathedral in Peru, Meccanica. (2018). doi:10.1007/s11012-017-0720-3.

[43] J. Ortega, G. Vasconcelos, H. Rodrigues, M. Correia, Assessment of the influence of horizontal diaphragms on the seismic performance of vernacular buildings, Bull. Earthq. Eng. (2018). doi:10.1007/s10518-018-0318-8.

[44] R. de Borst, Fracture in quasi-brittle materials: A review of continuum damagebased approaches, Eng. Fract. Mech. 69 (2001) 95-112. doi:10.1016/S00137944(01)00082-0.

[45] J. Mosler, G. Meschke, Embedded crack vs. smeared crack models: a comparison of elementwise discontinuous crack path approaches with emphasis on mesh bias, Comput. Methods Appl. Mech. Eng. 193 (2004) 3351-3375. doi:10.1016/j.cma.2003.09.022.

[46] T. Rabczuk, Computational Methods for Fracture in Brittle and Quasi-Brittle Solids : State-of-the-art Review and Future Perspectives, ISRN Appl. Math. 2013 (2012) 1-61. doi:10.1155/2013/849231.

[47] S. Saloustros, M. Cervera, L. Pelà, Challenges, Tools and Applications of Tracking Algorithms in the Numerical Modelling of Cracks in Concrete and Masonry Structures, Arch. Comput. Methods Eng. (2018) doi:10.1007/s11831-018-9274-3. (in press).

[48] M. Cervera, M. Chiumenti, R. Codina, Mixed stabilized finite element methods in nonlinear solid mechanics. Part I: Formulation, Comput. Methods Appl. Mech. Eng. 199 (2010) 2559-2570. doi:10.1016/j.cma.2010.04.006.

[49] M. Cervera, M. Chiumenti, R. Codina, Mixed stabilized finite element methods in nonlinear solid mechanics. Part II: Strain localization., Comput. Methods Appl. Mech. Eng. 199 (2010) 2571-2589. doi:10.1016/j.cma.2010.04.005.

[50] M. Cervera, M. Chiumenti, R. Codina, Mesh objective modeling of cracks using continuous linear strain and displacement interpolations, Int. J. Numer. Methods 
Eng. (2011). doi:10.1002/nme.3148.

[51] M. Cervera, M. Chiumenti, L. Benedetti, R. Codina, Mixed stabilized finite element methods in nonlinear solid mechanics. Part III: Compressible and incompressible plasticity, Comput. Methods Appl. Mech. Eng. 285 (2015) 752775. doi:10.1016/j.cma.2014.11.040.

[52] L. Benedetti, M. Cervera, M. Chiumenti, 3D numerical modelling of twisting cracks under bending and torsion of skew notched beams, Eng. Fract. Mech. (2017). doi:10.1016/j.engfracmech.2017.03.025.

[53] M. Cervera, G.B. Barbat, M. Chiumenti, Finite element modeling of quasi-brittle cracks in 2D and 3D with enhanced strain accuracy, Comput. Mech. (2017). doi:10.1007/s00466-017-1438-8.

[54] G.B. Barbat, M. Cervera, M. Chiumenti, Appraisement of planar, bending and twisting cracks in 3D with isotropic and orthotropic damage models, Int. J. Fract. 210 (2018) 1-35. doi:10.1007/s10704-018-0261-3.

[55] P.X. Candeias, A.C. Costa, N. Mendes, A.A. Costa, P.B. Lourenço, Experimental Assessment of the Out-of-Plane Performance of Masonry Buildings Through Shaking Table Tests, Int. J. Archit. Herit. 11 (2016) 1-28. doi:10.1080/15583058.2016.1238975.

[56] F. Brezzi, On the existence, uniqueness and approximation of saddle-point problems arising from Lagrangian multipliers, Rev. Française d'automatique, Informatique, Rech. Opérationnelle. Anal. Numérique. (1974). doi:10.1051/m2an/197408R201291.

[57] M. Cervera, Viscoelasticity and Rate-dependent Continuum Damage Models, Monography N-79, CIMNE, Barcelona, 2003.

[58] J. Lemaitre, J.L. Chaboche, Aspect Phenomenologique de la Rupture par Endommagement, J. Mécanique Appliquée. 2 (1978).

[59] Z.P. Bažant, B. Oh, Crack band theory for fracture of concrete, Mater. Struct. 16 (1983) 155-177. doi:10.1007/BF02486267.

[60] EN 1998-1 (Eurocode 8), Design of structures for earthquake resistance, Part 1 General rules seismic actions and rules for buildings, (2003).

[61] FEMA - Federal Emergency ManagementAgency, FEMA 440 - Improvement of nonlinear static seismic analysis procedures, Washington DC, 2005.

[62] CNR-DT 212/213, Guide for the Probabilistic Assessment of the Seismic Safety 
of Existing Buildings, Rome, Italy, 2014.

[63] L. Pelà, A. Aprile, A. Benedetti, Seismic assessment of masonry arch bridges, Eng. Struct. 31 (2009) 1777-1788. doi:10.1016/j.engstruct.2009.02.012.

[64] P.B. Lourenço, N. Mendes, L.F. Ramos, D. V. Oliveira, Analysis of Masonry Structures Without Box Behavior, Int. J. Archit. Herit. 5 (2011) 369-382. doi:10.1080/15583058.2010.528824.

[65] Y. Endo, M.S. Llorens, P. Roca, L. Pelà, Dynamic Identification and Static Loading Tests of Timbrel Vaults: Application to a Modernist 20th Century Heritage Structure, Int. J. Archit. Herit. 11 (2017) 607-620. doi:10.1080/15583058.2016.1277566.

[66] S. Saloustros, M. Cervera, L. Pelà, Tracking multi-directional intersecting cracks in numerical modelling of masonry shear walls under cyclic loading, Meccanica. 53 (2018) 1757-1776. doi:10.1007/s11012-017-0712-3.

[67] P.B. Lourenço, Recent Advances in Masonry Modelling: Micromodelling and Homogenisation, in: Multiscale Model. Solid Mech. Comput. Approaches, 2009: pp. 251-294. doi:10.1142/9781848163089_0006.

[68] C. Chácara, N. Mendes, P.B. Lourenço, Simulation of Shake Table Tests on Outof-Plane Masonry Buildings. Part (IV): Macro and Micro FEM Based Approaches, Int. J. Archit. Herit. (2017). doi:10.1080/15583058.2016.1238972.

[69] F. Cannizzaro, P.B. Lourenço, Simulation of Shake Table Tests on Out-of-Plane Masonry Buildings. Part (VI): Discrete Element Approach, Int. J. Archit. Herit. 11 (2017) 125-142. doi:10.1080/15583058.2016.1238973.

[70] G. Vlachakis, Out-of-plane simulation of masonry structures using novel finite element techniques, MSc thesis Universitat Politècnica de Catalunya, UPCBarcelonaTech, 2017.

[71] COMET, Coupled Mechanical and Thermal analysis, http://www.cimne.com/comet/, (2016).

[72] M. Cervera, C. Agelet de Saracibar, M. Chiumenti, COMET - data input manual version 5.0. Technical report IT-308, Barcelona, 2002.

[73] GiD v.13, The personal pre and post-processor, http://www.gidhome.com/, (2017).

[74] A.A. Costa, A. Arêde, A.C. Costa, A. Penna, A. Costa, Out-of-plane behaviour of a full scale stone masonry façade. Part 2: shaking table tests, Earthq. Eng. Struct. Dyn. 42 (2013) 2097-2111. doi:10.1002/eqe.2314.

[75] N. Mendes, A.A. Costa, P.B. Lourenço, R. Bento, K. Beyer, G. De Felice, M. 
Gams, M.C. Griffith, M. Jason, S. Lagomarsino, J. V Lemos, D. Liberatore, C. Modena, D. V. Oliveira, A. Penna, L. Sorrentino, Methods and Approaches for Blind Test Predictions of Out-of-Plane Behavior of Masonry Walls : A Numerical Comparative Study, Int. J. Archit. Herit. $11 \quad$ (2017) 59-71. doi:10.1080/15583058.2016.1238974.

[76] P.B. Lourenço, J.G. Rots, J. Blaauwendraad, Continuum Model for Masonry: Parameter Estimation and Validation, J. Struct. Eng. 124 (1998) 642-652. doi:10.1061/(ASCE)0733-9445(1998)124:6(642).

[77] L. Pelà, Continuum Damage Model for Nonlinear Analysis of Masonry Structures, PhD thesis, Universitat Politècnica de Catalunya (UPC-BarcelonaTech), 2009. http://eprints.unife.it/87/. 